$40(1) \mid 2011$

Varia

\title{
La configuración arquitectónica de los ushnus como espacios de libaciones y ofrendas líquidas durante el Tahuantinsuyo
}

La configuration architecturale des ushnus comme espaces de libations et d'offrandes liquides à l'époque du Tahuantinsuyo

The architectural configuration of the ushnus spaces as liquid libations and offerings during the Tahuantinsuyo

\section{Luis Rodolfo Monteverde Sotil}

\section{OpenEdition}

Journals

Edición electrónica

URL: http://journals.openedition.org/bifea/1635

DOI: $10.4000 /$ bifea. 1635

ISSN: 2076-5827

Editor

Institut Français d'Études Andines

Edición impresa

Fecha de publicación: 1 abril 2011

Paginación: 31-80

ISSN: 0303-7495

Referencia electrónica

Luis Rodolfo Monteverde Sotil, «La configuración arquitectónica de los ushnus como espacios de libaciones y ofrendas líquidas durante el Tahuantinsuyo », Bulletin de l'Institut français d'études andines [En línea], 40 (1) | 2011, Publicado el 01 octubre 2011, consultado el 10 diciembre 2020. URL : http:// journals.openedition.org/bifea/1635; DOI : https://doi.org/10.4000/bifea.1635

\section{(c) (†) $\ominus$}

Les contenus du Bulletin de l'Institut français d'études andines sont mis à disposition selon les termes de la licence Creative Commons Attribution - Pas d'Utilisation Commerciale - Pas de Modification 4.0 International. 


\title{
La configuración arquitectónica de los ushnus como espacios de libaciones y ofrendas líquidas durante el Tahuantinsuyo
}

\author{
Luis Rodolfo Monteverde Sotil*
}

\begin{abstract}
Resumen
Para el autor del artículo, las principales actividades realizadas en los ushnus por los incas habrían sido las libaciones y ofrendas líquidas. Por tal motivo, los ushnus fueron implementados arquitectónicamente con pozos y canales. Primero se propone definir cómo fueron los ushnus del Cuzco, luego se analizarán los ushnus localizados fuera de esta llacta, para posteriormente ver sus diferencias y similitudes. Asimismo, se evaluará si el dato etnográfico puede servir para entender, sumado a la evidencia arqueológica e información etnohistórica, la funcionalidad de los ushnus en lo que respecta a su configuración arquitectónica como espacios de libaciones y ofrendas líquidas durante el Tahuantinsuyo.
\end{abstract}

Palabras clave: ushnus, culto al agua, administración estatal inca

\section{La configuration architecturale des ushnus comme espaces de libations et d'offrandes liquides à l'époque du Tahuantinsuyo}

\section{Résumé}

Pour l'auteur de l'article, les principales activités réalisées par les Incas sur les ushnus auraient consisté en des libations et offrandes liquides. Voilà pourquoi semble-t-il, les ushnus étaient équipés de puits el de canaux d'irrigation.L'auteur explique la fonction des ushnus à Cuzco, puis analyse leur localisation hors de cette région pour observer, a posteriori, leurs différences et leurs similitudes. De cette manière, l'auteur tente de voir si l'information ethnographique, en corrélation avec les trouvailles archéologiques, peut aider à comprendre la fonction des ushnus dans leur configuration architecturale comme espace de libations et d'offrandes liquides à l'époque du Tahuantinsuyo.

* Maestría en Arqueología en la PUCP, Bachillerato en Arqueología en la UNFV, Egresado de Historia del Arte en la UNMSM, Calle Libertad 119 Santa Patricia La Molina, Lima-Perú. E-mail: Laspuertas48@hotmail.com 
Mots clés : ushnus, culte dédié à l'eau, administration de l'état Inca

\title{
The architectural configuration of the ushnus spaces as liquid libations and offerings during the Tahuantinsuyo
}

\begin{abstract}
For the archaeologists the main activities by the Incas at ushnus would have been liquid libations and offerings. For this reason, ushnus were equipped with wells and canals. In the present article the author first defines the nature of ushnus of Cuzco, then analyzes the ushnus located outside this llacta, and later examines their differences and similarities. Also, he see if the ethnographic data in addition to the archaeological and ethnohistorical information, can help us understand the functionality of ushnus in regard to their architectural configuration as spaces for liquid libations and offerings during the Tahuantinsuyo
\end{abstract}

Keywords: ushnus, cult to water, Inca state administration

\section{INTRODUCCIÓN}

La propuesta del presente artículo es plantear que las ceremonias político religiosas de libaciones y ofrendas líquidas hayan sido las principales actividades realizadas por los incas en los ushnus. No por ello se descarta ahí la realización e importancia de otros tipos de cultos y actividades (observaciones astronómicas, capacochas, etc.). En efecto pensamos que todos ellos habrían estado relacionados y organizados en beneficio, por ejemplo, de la producción agrícola donde las ofrendas líquidas y las ceremonias de libaciones habrían tenido un rol resaltante. Es la razón por la cual los ushnus presentan una implementación arquitectónica de pozos y canales en los cuales se llevaban a cabo estas ofrendas y ceremonias.

La cultura puede ser definida como las relaciones humanas que se establecen a diario en un determinado grupo social (Lumbreras, com. pers., 2008). Donde la ideología, conjunto de ideas que caracterizan al pensamiento humano (Diccionario de la Lengua Española, 2001, tome 6: 844), es un componente integral que configura dichas relaciones (DeMarrais et al., 1996) y la cosmología la armazón que explica la interacción armónica entre este grupo y el mundo que habita (Topic, 2008), es decir las leyes generales que rigen el mundo físico (Diccionario de la Lengua Española, 2001, tomo 4: 455). Es por eso que, tanto la ideología como la cosmología «enmarcan» el desarrollo cultural de un determinado grupo humano; donde ambas son compartidas y aceptadas, mas no impuestas. Por ello las ideologías y cosmologías defendidas por el incanato deben ser entendidas más allá de un mero mecanismo de legitimación (Topic, 2008) o de imposición del poder sobre los pueblos anexados al Tahuantinsuyo.

La ideología y la cosmología tienen que ser materializadas por todo grupo social (DeMarrais et al., 1996); en este caso, el imperio del Tahuantinsuyo con el Inca a la cabeza. Dicha materialización se da a través de la arquitectura (como es el caso de 
los ushnus), la cerámica, la textilería, etc., es decir, a través de la cultura material, de forma concreta, para hacer posible las acciones estatales emprendidas. Pero, al contrario de DeMarrais et al. (1996), el autor piensa que dicha materialización no sirve solo para la manipulación unilineal, donde los únicos beneficiados son los que controlan (o sea los incas). En este caso, es más bien, recíproca (no con ello necesariamente simétrica), donde los controlados también se benefician (es decir los pueblos anexados al Tahuantinsuyo). Ahí justamente radicaría la pluralidad de las estrategias político religiosas empleadas por los incas a lo largo de los años y del territorio sudamericano, señaladas por algunos autores (p. ej. D'Altroy, 2003).

La arquitectura, así como los procesos de producción metalúrgica o de cerámica no operan exclusivamente en la esfera tecnológica, puesto que implican, y siempre son productos, de sistemas sociales. Eso se debe a que los mismos se encuentran integrados estrechamente a contextos de uso social, dentro de la cultura mental y material, las cuales no deben ser entendidas por separado (Tilley, 1989). Se entiende, por ende, a la arquitectura (cultura material) como un medio de comunicación involucrado en la práctica social, y que puede ser usada para transformar y almacenar información social (cultura mental: ideología, cosmología, etc.) o viceversa. Es el caso, por ejemplo, del nuevo orden establecido por el Tahuantinsuyo y sus complejas y variadas interacciones sociales con los pueblos que pasaron a formar parte de este imperio. Es por eso que formalmente encontramos una gran variedad en las características arquitectónicas de los ushnus del Perú y otros países de Sudamérica (p. ej. Chile y Argentina).

Como se podrá apreciar, el modelo a seguir de los ushnus cuzqueños (localizados en las plazas Haucaypata y Hurin Haucaypata) habría consistido en repetir básicamente sus modelos funcionales, rituales y simbólicos, como lo fue con los demás edificios, plazas y canchas de la capital imperial (Gasparini \& Margolies, 1977), con la clara intención de materializar la ideología y cosmología defendida desde el Cuzco. Es por ello que los pozos construidos en los ushnus fueron de suma importancia, ya que en ellos se recrearían las ceremonias de libaciones y ofrendas líquidas propulsadas desde la capital imperial y estratégicamente adecuadas, en muchos casos, a las ideologías y cosmologías de los pueblos locales. Pero, las características monumentales, arquitectónicas y tecnológicas de los ushnus variaron de un asentamiento al otro, debido básicamente, como se cuenta, a contextos de interacciones sociales (estrategias políticas, religiosas, geopolíticas, tradiciones constructivas, recursos técnico materiales, etc.) entre el Tahuantinsuyo y los nuevos pueblos anexados al imperio.

Tomando como base una contextualización interdisciplinaria entre las evidencias arqueológicas (entiéndase descripción, comparación y análisis de una determinada muestra de ushnus del Cuzco y de asentamientos incaicos localizados fuera de esta llacta), información etnohistórica y etnográfica, se propone resolver las siguientes interrogantes con la intención de analizar la configuración arquitectónica de los ushnus como espacios de libación y ofrendas líquidas: (1) ¿cómo eran los ushnus de las plazas principales del Cuzco?; (2) ¿cuáles son las características arquitectónicas y arqueológicas recurrentes en los ushnus localizados en asentamientos fuera 
del Cuzco?; (3) iexisten similitudes arquitectónicas entre los ushnus del Cuzco y los localizados fuera de la llacta cuzqueña?; y (4) ien el pensamiento andino contemporáneo existe alguna relación entre el concepto ushnu, ofrendas líquidas y libaciones, no de manera idéntica pero sí con ciertas similitudes a las de las épocas del Tahuantinsuyo?

\section{LOS USHNUS DEL CUZCO}

Se conoce muy poco sobre el ushnu de la plaza Haucaypata (hoy plaza de Armas del Cuzco), el Hurin Haucaypata (o plaza Limacpampa Grande, al este del Templo del Sol según Zuidema, 1979; 1989; 19911) (ver fig. 1) u otros. En general la arqueología cuzqueña nos ha brindado escasas luces sobre el Cuzco prehispánico (ver Oberti, 1983 y Bauer, 2008 quienes opinan al respecto). A la fecha se cuenta solamente con un dato arqueológico obtenido en una excavación en la plaza de Armas del Cuzco que puede brindar cierto aporte para poder aproximarse a las características materiales del ushnu de la plaza Haucaypata. Según Farrington \& Raffino (1996) y Vargas (2007), se encontraron en excavaciones arqueológicas realizadas por arqueólogos del INC-Cuzco, junto a la pileta de la plaza de Armas, alineamientos de piedras de factura inca (Farrington \& Raffino, 1996) asociados a figurinas de camélidos (una de Spondylus, otra de oro y dos de plata) halladas en un sector aledaño y a $80 \mathrm{~cm}$ de la superficie (Vargas, 2007). Lamentablemente es todo lo que se sabe de esta excavación (Vargas, 2007).

Por ello, el presente capítulo pretende, en base a una revisión crítica de las fuentes etnohistóricas, analizar las características arquitectónicas o formales del ushnu de la plaza Haucaypata, Hurin Haucaypata u otra de la capital del imperio del Tahuantinsuyo. Pero al mismo tiempo, se valdrá del dato arqueológico para poder realizar una serie de comparaciones entre diversos asentamientos arqueológicos en y fuera del Cuzco, en los cuales se pueda encontrar evidencias materiales que ayuden a comprender cómo fueron los ushnus cuzqueños descritos por los cronistas.

\section{1. Fuentes etnohistóricas}

A continuación se analiza cómo pudieron haber sido los ushnus de las plazas cuzqueñas (ver cuadro 1), en base a las descripciones de siete cronistas del siglo XVI, ordenadas cronológicamente: Juan de Betanzos (2010 [1551]); Pedro Cieza de León (1986 [1553]); Anónimo (1906 [Circa 1565]); Pedro Pizarro (1986 [1571]); Cristóbal de Molina (2008 [1574-1575]); Cristóbal de Albornoz (in Duviols 1984 [1582]); Bernabé Cobo (in: Rowe, 1981 [1653]).

1 Bauer (2000) acepta como tentativa la localización de este ushnu en la plaza de Limacpampa Grande. 


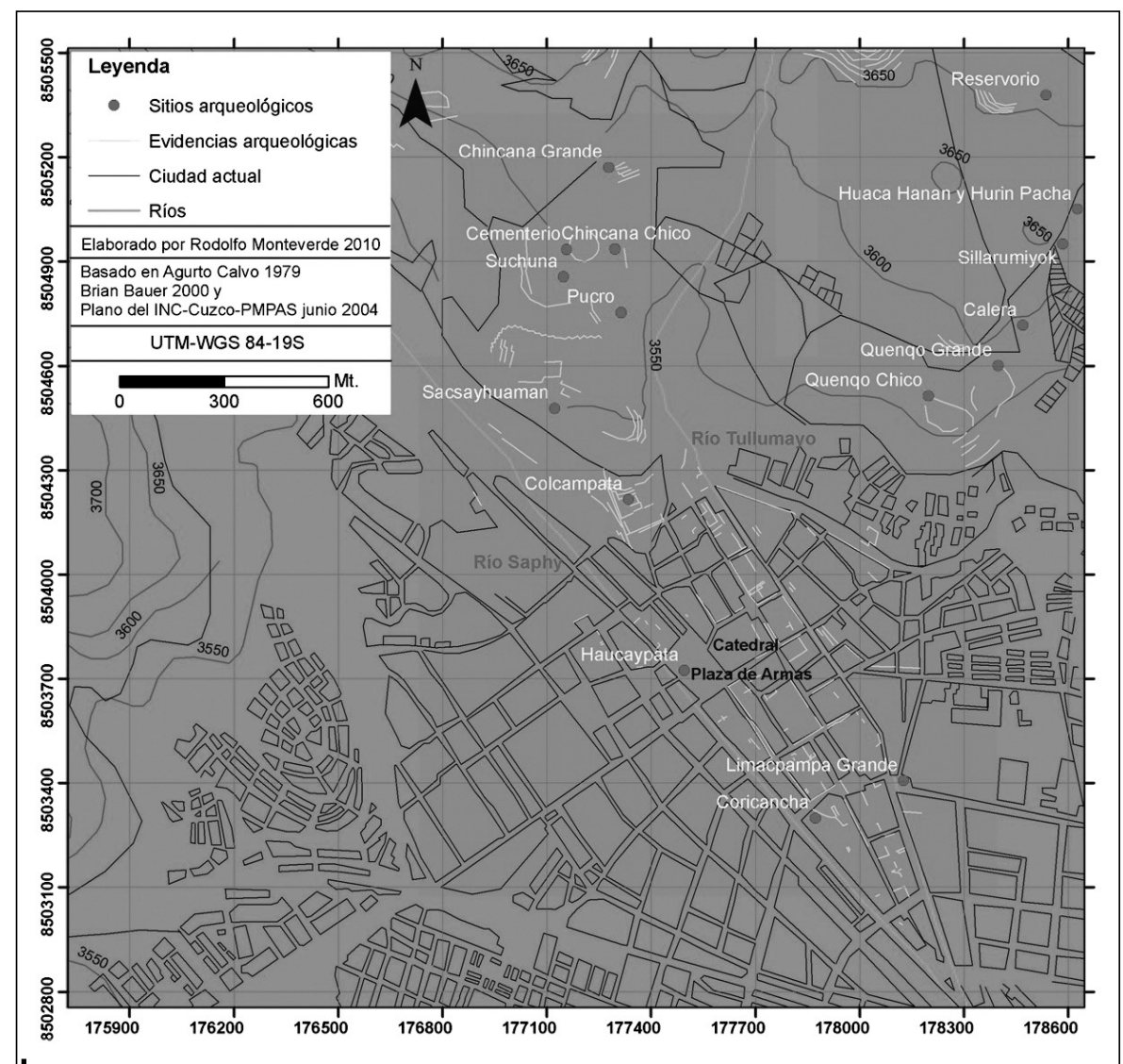

Figura 1 - Vista del sector monumental del Cuzco y del lado SW del Parque Arqueológico de Sacsayhuamán

Se aprecia la localización de algunas de las construcciones del Tahuantinsuyo localizadas en el sector monumental del Cuzco (entre los ríos Tullumayo y Saphy) donde destacan las plazas Haucaypata (plaza de Armas) y Hurin Haucaypata (plaza Limacpampa Grande). Ahí, según las crónicas, cada una tenía un ushnu. Plano diseñado por Rodolfo Monteverde Sotil, 2010.

\section{1. 1. Juan de Betanzos (2010: $94-95$ [1551: Cap. XI])}

Este capítulo trata sobre la casa del Sol, el bulto del Sol y los ayunos que mandó hacer Inca Yupanqui. Betanzos menciona que no todos podían entrar al Templo del Sol a menos que fueran señores, por ello:

«... hizo poner en medio de la plaza del Cuzco donde ahora es el royo una piedra de la hechura de un pan de azúcar puntiaguda para arriba y enforrada e una faja de oro la cual piedra hizo ansi mismo labrar el día que mandó hacer el bulto del sol...».

Luego señala que:

«... la piedra se puso en medio de la plaza del Cuzco hízose en ella [la plaza] un gran hoyo primero donde todos los de la ciudad chicos y grandes 
Cuadro 1 - En este esquema se aprecian las características formales básicas y recurrentes del ushnu del Haucaypata, Hurin Haucaypata y de la chacara de Gualparocas que son mencionadas por los cronistas del siglo XVI en alusión a los ushnus del Cuzco

Rodolfo Monteverde Sotil, 2010

\begin{tabular}{|c|c|c|c|c|c|c|c|}
\hline \multirow[t]{2}{*}{ Cronista } & & \multicolumn{6}{|c|}{ Ushnus del Cuzco y de los elementos materiales que lo conforman } \\
\hline & Localización & Piedra & Pila o pozo & Canales & Oro & Otros & Denominación \\
\hline $\begin{array}{c}\text { Juan de } \\
\text { Betanzos } \\
{[1551]}\end{array}$ & $\begin{array}{c}\text { En medio de } \\
\text { la plaza del } \\
\text { Cuzco }\end{array}$ & $\begin{array}{l}\text { Era una piedra } \\
\text { con la forma } \\
\text { de un pan } \\
\text { de azúcar } \\
\text { puntiaguda } \\
\text { para arriba }\end{array}$ & $\begin{array}{c}\text { La piedra } \\
\text { estaba en } \\
\text { medio de } \\
\text { una pila } \\
\text { de cantería } \\
\text { de medio } \\
\text { estado de } \\
\text { alto (aprox. } \\
0,84 \mathrm{~m} \text { ) }\end{array}$ & & $\begin{array}{l}\text { La piedra } \\
\text { estaba } \\
\text { forrada con } \\
\text { una faja de } \\
\text { oro }\end{array}$ & & \\
\hline $\begin{array}{c}\text { Pedro } \\
\text { Cieza } \\
\text { de León } \\
\text { [1553] }\end{array}$ & $\begin{array}{c}\text { En la gran } \\
\text { plaza de la } \\
\text { ciudad del } \\
\text { Cuzco }\end{array}$ & $\begin{array}{l}\text { Era una piedra } \\
\text { grande, de } \\
\text { la forma y } \\
\text { hechura de } \\
\text { un pan de } \\
\text { azúcar }\end{array}$ & ------------ & - & $\begin{array}{l}\text { La piedra } \\
\text { estaba } \\
\text { engastada y } \\
\text { llena de oro }\end{array}$ & ----- & \\
\hline $\begin{array}{l}\text { Anónimo } \\
\text { [Circa } \\
1565]\end{array}$ & $\begin{array}{l}\text { En medio } \\
\text { de la plaza } \\
\text { principal } \\
\text { Haucaypata }\end{array}$ & $\begin{array}{c}\text { Era un pilar de } \\
\text { piedra labrado } \\
\text { de un estado } \\
\text { de alto (aprox. } \\
1,68 \mathrm{~m})\end{array}$ & --------- & -------- & ----------- & $\begin{array}{l}\text { Había un } \\
\text { teatro de } \\
\text { piel de } \\
\text { corderos, } \\
\text { telas y } \\
\text { muchas } \\
\text { cosas más }\end{array}$ & Osno \\
\hline $\begin{array}{l}\text { Pedro } \\
\text { Pizarro } \\
{[1571]}\end{array}$ & $\begin{array}{c}\text { En la mitad } \\
\text { de la plaza } \\
\text { (Haucaypata) }\end{array}$ & $\begin{array}{c}\text { Era una piedra } \\
\text { redonda a } \\
\text { manera de } \\
\text { teta }\end{array}$ & $\begin{array}{c}\text { Tenía una } \\
\text { alberca } \\
\text { alrededor de } \\
\text { la piedra }\end{array}$ & $\begin{array}{l}\text { Unos canales } \\
\text { subterráneos, } \\
\text { salían de la } \\
\text { alberca }\end{array}$ & $\begin{array}{l}\text { La piedra } \\
\text { tenía una } \\
\text { funda de } \\
\text { oro }\end{array}$ & $\begin{array}{l}\text { Un buhío } \\
\text { de forma } \\
\text { redonda la } \\
\text { cubría de } \\
\text { noche }\end{array}$ & \\
\hline $\begin{array}{c}\text { Cristóbal } \\
\text { de Molina } \\
\text { [1574- } \\
1575]\end{array}$ & $\begin{array}{c}\text { En medio de } \\
\text { la plaza del } \\
\text { Cuzco }\end{array}$ & & $\begin{array}{c}\text { Era a manera } \\
\text { de una pila } \\
\text { de piedra }\end{array}$ & $\begin{array}{c}\text { Unos canales } \\
\text { salían de la } \\
\text { pila e iban a } \\
\text { las casas del } \\
\text { Sol el Trueno } \\
\text { y el Hacedor }\end{array}$ & $\begin{array}{c}\text { La pila } \\
\text { estaba } \\
\text { forrada en } \\
\text { oro }\end{array}$ & & Usño \\
\hline $\begin{array}{c}\text { Cristóbal } \\
\text { de } \\
\text { Albornoz } \\
[1582]) \\
\end{array}$ & $\begin{array}{c}\text { En la plaza } \\
\text { (Haucaypata) }\end{array}$ & & - & - & $\begin{array}{l}\text { Era un pilar } \\
\text { de oro }\end{array}$ & & Usno \\
\hline $\begin{array}{c}\text { Bernabé } \\
\text { Cobo } \\
\text { [1653] }\end{array}$ & $\begin{array}{c}\text { (1) En } \\
\text { la plaza } \\
\text { del Hurin } \\
\text { Haucaypata } \\
\text { / (2) En la } \\
\text { chacara } \\
\text { de los } \\
\text { Gualparocas } \\
(¿ ?)\end{array}$ & $\begin{array}{l}\text { (1) Era una } \\
\text { piedra (2) Era } \\
\text { una piedra no } \\
\text { muy grande }\end{array}$ & & 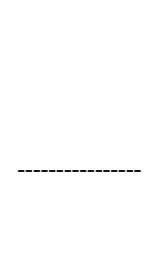 & - & 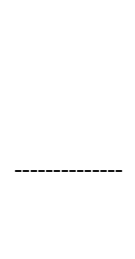 & $\begin{array}{c}\text { (1) Uzno / (2) } \\
\text { Oznuro }\end{array}$ \\
\hline
\end{tabular}


ofrescieron al sol las piezas de oro que les pareció y esto ofrecido cerraron el hoyo encima del cual hicieron y edificaron una pila de cantería de altor de medio estado [aprox. $0,84 \mathrm{~m}^{2} \mathrm{y}$ en la redondez de la pila enterraron unos bultos de oro de largor de un dedo y del mismo gordor cada uno y estos bulticos que ansi enterraron en torno a la pila... y puestos en este orden los metieron debajo de la tierra de dentro de la pila... y en medio de la pila pusieron la piedra...».

Como hemos podido leer este cronista no denomina a esta piedra como ushnu.

\section{1. 2. Pedro Cieza de León (1986: 69 [1553: fol. 30v.])}

En la segunda parte de su crónica Cieza menciona, sin emplear el término ushnu, que:

«... en la gran plaza de la ciudad del Cuzco, estaua la piedra de la guerra que era grande, de la forma y hechura de un pan de azúcar, bien engastada y llena de oro...».

\section{1. 3. Anónimo (1906: 151 y 158 [Circa 1565])}

Señala que:

«... en medio de la plaza tenía un pilar de piedra muy labrada, de un estado de alto $[1,6718 \mathrm{~m}] \ldots$ que le nombrauan Osno...».

$\mathrm{Y}$ al describir las actividades que se realizaban en setiembre o Cituaquilla [Situa] señala que:

«... en este mes se juntauan en el Cuzco todos los indios de toda la comarca, y juntos todos en la plaza principal, llamada Haocaypata, y allí hazían sus sacrificios al Sol con muchas ceremonias, en un pilar de piedra que tenían en medio de la plaza, con su teatro llamado Osno, y los hazían de corderos y rropas de precio y otras muchas cosas, y al pie del teatro vertían mucha chicha... que la ofrecían al Sol...».

En esta cita el cronista ya emplea el término Osno.

\section{1. 4. Pedro Pizarro (1986: 89 - 90 [1571: 53 y 53v])}

Aunque tampoco emplea el término ushnu, comenta que cuando sacaban a los muertos a la plaza del Cuzco ponían delante de ellos:

«... unos... verquis de oro o de plata o de barro... y aquí echaban la chicha... Pues llenos estos verquis los derramaban en una piedra redonda que tenían por ídolo, en mitad de la plaza [Haucaypata], y echo alrededor una alberca pequeña a donde se consumía por unos caños que ellos tenían hechos por debajo de tierra... Esta piedra tenía una funda de oro que

2 Según Agurto Calvo (1987: 277) un estado es una antigua medida española de longitud que equivale a $1,6718 \mathrm{~m}$. 
encaxaua en ella y la tapaba toda, y asimismo tenía hecho una manera de buhihuelo [buhío3] de esteras texidas, redondo, con que la cubrían de noche».

Luego añade que cuando quemaban la comida del sol en la plaza las

«... cenizas que quedaban de estos fuegos que hacían... las echaban en este pilón que digo estaba en mitad de las plazas y piedra redonda a manera de teta...».

1. 1. 5. Cristóbal de Molina (2008: 155 y 160 [1574-1575: fol. 11v. y fol. 14r.])

En su relato de la fiesta de la Situa, Molina menciona que

«... luego la gente... salía a la plaza del Cuzco [Haucaypata] 4 ... y en la plaza en medio della a do estaua el usño de oro que era a manera de pila a donde echauan el sacrificio de la chicha...».

Líneas más adelante, Molina agrega que, al pedírsele al Hacedor, al Sol y al Trueno, con los cuales bebía el inca, para que les llegase otro año sin enfermedades que:

«... tenia el sol delante de si vn uasso de oro grande en que hechaua el ynca chicha y de allí el sacerdote se le tomaua y la hechaua en el usño que como dicho es es a manera de pila de piedra enforrada en oro la qual tenia vn abujero debajo de tierra hasta las cassas del sol y el trueno y Hacedor ...».

\section{1. 6. Cristóbal de Albornoz (in: Duviols 1984: 256 [1582])}

En su lista de las huacas de la región del Chinchaysuyo del Cuzco Albornoz menciona que «...usno era un pilar de oro donde bevían al Sol en la plaza...». Albornoz no especifica el nombre de la plaza, pero al ser este ushnu una huaca del Chinchaysuyo y al estar el Haucaypata en esta región suponemos que el autor se refiere a esta plaza.

\section{1. 7. Bernabé Cobo (in: Rowe, 1981: 232 [1653])}

En su relación de las huacas del Cuzco, Cobo menciona que la primera huaca del quinto ceque del Antisuyo [An. 5: 1] era:

3 Buhío o Bohío: cabaña de América, hecha de madera y ramas, cañas o pajas (Diccionario de la lengua española, 2001, tomo 2: 224).

4 Cristóbal de Molina no menciona explícitamente el nombre de la plaza desde donde 400 personas agrupadas alrededor del ushnu partían en dirección a los cuatro suyos a arrojar los males fuera del Cuzco. Pensamos que Molina se refiere al ushnu del Haucaypata y no al del Hurin Haucaypata, ya que el Haucaypata era la plaza principal de la llacta cuzqueña, de donde partían los cuatro caminos principales a los cuatro suyos y en términos generales era el centro simbólico de la Situa (Monteverde, 2010). Santillana (2001: 263) también menciona que esta es la plaza señalada por Molina. Además, Garcilaso de la Vega (2005 [1609: Lib. 7mo, Cap. VI y VII]), señala que partían no 400 sino cuatro personas en dirección a los cuatro suyos durante la Situa, desde la actual plaza de Armas del Cuzco. Por ello, para nosotros Zuidema (1979: 326) comete un error de interpretación del relato de la Situa de Molina al comentar que era desde el ushnu del Hurin Haucaypata de donde salían 400 personas en dirección de los cuatro suyos. 
Tahuantinsuyo: la arquitectura de los ushnus como espacios de libaciones y ofrendas líquidas

«... una piedra llamada usno... en la plaza del Hurin aucaypata...».

Aunque Cobo no menciona el ushnu del Haucaypata5, refiere que la primera huaca del decimocuarto ceque del Cuntisuyo [Cu.14: 1] (in: Rowe, 1981: 243 [1653]):

«... era una piedra no muy grande llamada oznuro6 que estaua en la chacara de los Gualparocas...».

Como hemos podido notar, las primeras referencias al ushnu de la plaza Haucaypata se remontan a 1551 (con Betanzos), a solamente 17 años de la fundación española de la ciudad del Cuzco (1534) y se prolongan, manteniendo cierta recurrencia y similitudes entre ellas, hasta entrada la década del 80 del siglo XVI. Hay que recordar que es probable que la relación de Cobo, fechada en 1653, haya sido redactada entre 1559 y 1572 (Rowe, 1981; Bauer, 2000). Pero las primeras denominaciones o empleo de un nombre propio para denominarlos como Osno (Anónimo), Usño (Molina) o Usno (Albornoz y Cobo) se dan a partir de los años 60 de ese siglo (ver cuadro 1).

Posteriormente, en el siglo XVII, las descripciones del ushnu del Cuzco, como la de Guamán Poma de Ayala (2008: 303 [1615: lámina 398]), se diferencian enormemente de las crónicas del siglo que le antecede. Así, Guamán Poma dibuja el ushnu del Cuzco como plataformas superpuestas, a modo de pirámide trunca, encima de las cuales está sentado Manco Inca (uno de los Incas rebeldes de Vilcabamba). Su recreación es muy similar a otra que realiza del ushnu de Cajamarca (2008: 292 [1615: lámina 384]) y al mismo tiempo es muy parecida a la versión, de este mismo ushnu, de Martín de Murúa (2004 [1590: lib. 2do, cap. 10]) (ver fig. 2), donde incluso el Inca está sedente en una suerte de silla colocada sobre el ushnu.

El autor piensa que en el caso del ushnu del Cuzco, la recreación de Guamán Poma estaría alejada de la realidad:

(1) no solo por ser una representación tardía [1615] que representa a Manco Inca sentado sobre este ushnu;

(2) estar probablemente basada en un ushnu foráneo ( $p$ ej. Vilcashuamán, como también lo haría el cronista Santa Cruz Pachacuti Yamqui, 1995 [1613]7);

(3) porque sus láminas tienen una fuerte influencia iconográfica de catálogos europeos medievales que llegaron a América para que fueran usados como modelos en la decoración pictórica de algunas iglesias del interior del Perú,

5 Se acepta que la Relación de Huacas de Bernabé Cobo es incompleta (Rowe, 1981; Bauer, 2000) ya que no menciona, entre otros edificios y lugares de la capital incaica, el ushnu de la plaza Haucaypata, estructura de suma importancia en el Cuzco.

6 Oznuro, Osno, Usnu, Vsno, Usnuni, Usño, Uzno, Ozno, Husnu y Usmo son algunos de los términos empleados en las crónicas coloniales para referirse a lo que convencionalmente hoy se denomina como ushnu (Pino, 2010). La localización de oznuro es desconocida (Bauer, 2000).

7 «... y después de aber acabado trae a la plaza de haocay pata y en donde tenía su capac usno como en villcas y se asienta allí...» (1995: 92 [1613: fol. 32r.]) 


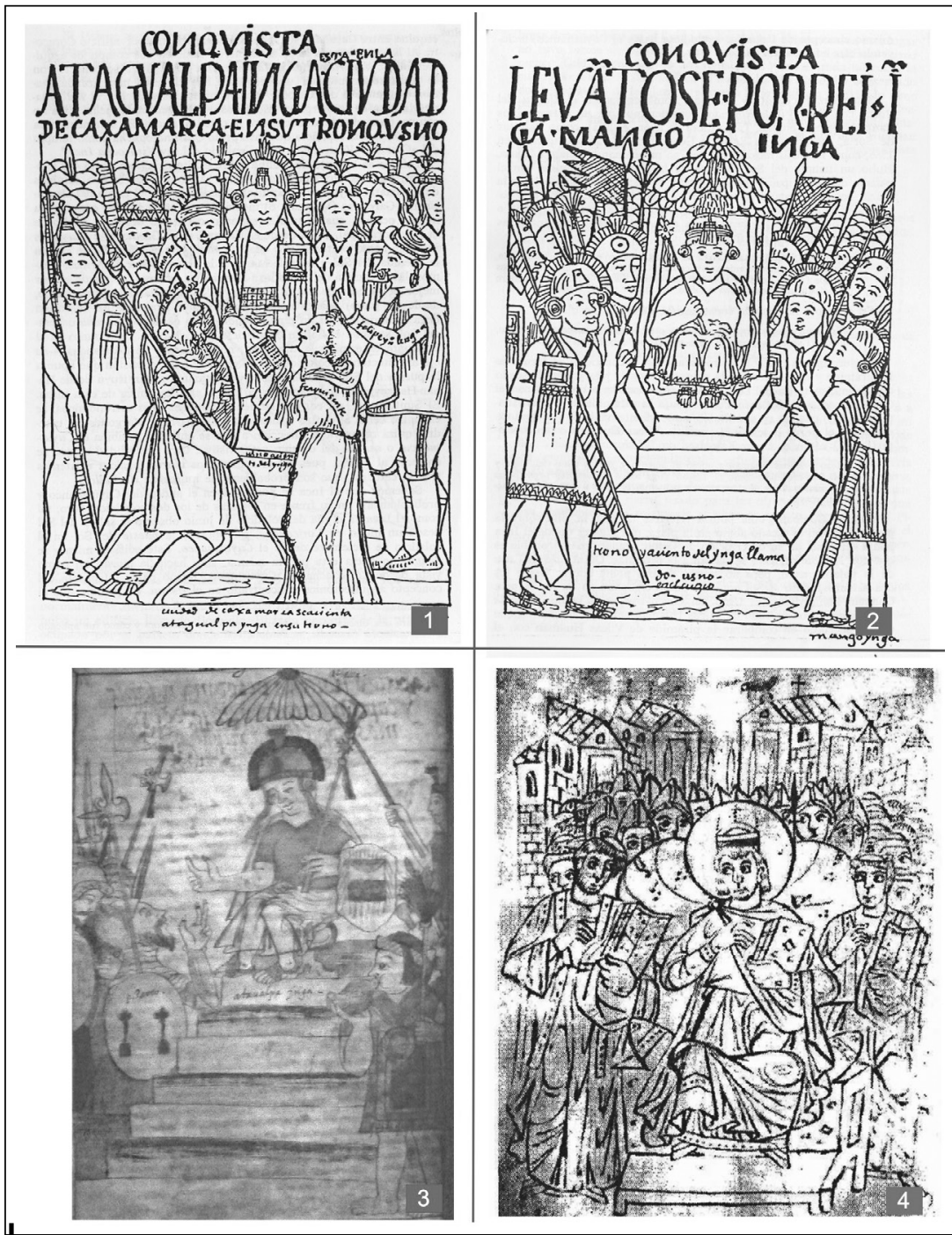

Figura 2 - Comparaciones entre las ilustraciones gráficas de Guamán Poma y Martín de Murúa y la probable influencia de las estampas medievales europeas en lo que concierne a la representación del ushnu como asiento del Inca

Lámina elaborada por Rodolfo Monteverde Sotil, 2010

los cuales probablemente también fueron usados por el que graficó la obra de Murúa, de ahí su parecido con Guamán Pomas (Holland, 2008).

8 Por ello se encuentra grandes similitudes entre las láminas de los ushnus de ambos autores con una lámina medieval del año 900 d. C. que representa al rey Teodosio sentado en su trono y rodeado por su consejo (ver fig. 2). Guamán Poma y Murúa quisieron resaltar que estos ushnus eran el trono del Inca. 
Los cronistas del siglo XVI que se refieren a los ushnus cuzqueños, hacen alusión a una plaza, que la mayoría coincide en denominar del Cuzco, principal, Haucaypata, Hoacaypata. Otros como Cobo mencionan la plaza de Hurin Haucaypata (hoy plaza Limacpampa Grande) y la «... chacara de los Gualparocas...» cuya ubicación se desconoce en la actualidad. Asimismo, muchos de ellos coinciden que

(1) el ushnu se localizaba en la parte media del Haucaypata;

(2) que era una piedra de forma ovalada, como un pan de azúcar o redonda pero puntiaguda;

(3) que era de tamaño grande, Anónimo dice de un estado de alto (aproximadamente 1,6718 m);

(4) que esta piedra estaba rodeada por una pila, pozo o alberca de piedra de aproximadamente unos 0,84 metros de alto (medio estado de alto, según Betanzos);

(5) que de esta pila salían canales subterráneos;

(6) para algunos, tanto la piedra como la pila tenían una cubierta hecha en oro (ver cuadro 1).

Si nos valemos de las evidencias materiales que los arqueólogos del INC-Cuzco (ver Farrington \& Raffino, 1996; Vargas, 2007) hallaron en sus excavaciones:

(1) al lado de la pileta de la plaza de Armas del Cuzco, o sea «en el Haucaypata»;

(2) evidenciando alineamientos de piedras de factura inca que resultaron ser cimientos de muros de contención de alguna estructura, nos preguntamos «¿̇no serían de la pila o la alberca del ushnu?» ¿Acaso Juan de Betanzos (2010: 95 [1551: Cap. XI]) no dice que «... la piedra se puso en medio de la plaza del Cuzco [donde] hízose en ella un gran hoyo primero...?»;

(3) si estos muros estaban asociados a cuatro figurinas de camélidos, nos volvemos a preguntar iacaso Betanzos (2010: 95 [1551: Cap. XI]) no menciona que

«... y en la redondez de la pila enterraron unos bultos de oro de largor de un dedo y del mismo gordor cada uno y estos bulticos que ansi enterraron en torno a la pila...»?

Estos datos arqueológicos, sumados a la información etnohistórica, nos invitan a la discusión.

Asimismo, los cronistas del siglo XVI no hacen alusión a los ushnus de la plaza Haucaypata, Hurin Haucaypata u otra del Cuzco como una estructura arquitectónica de una gran o más plataformas superpuestas o a modo de un edificio, como lo hiciera Cristóbal de Albornoz (in: Duviols, 1984: 202 [1582]) al referirse a los ushnus de Vilcashuamán (Ayacucho) y Huánuco Pampa (Huánuco):

«... hay otra guaca... en las plazas de los pueblos que llaman uznos... eran un bolo hecho de muchas piedras o de oro y plata... a todos les tenían hechos edificios... a hechura de torres de muy hermoza cantería... hanze de deshacer estos edificios que como son públicos...» (recuérdese que Albornoz también describe al ushnu de la plaza Haucaypata). 
La pregunta sería ¿por qué no se mencionan, de haber existido, estas características arquitectónicas de los ushnus del Cuzco?

Zuidema $(1979 ; 1989 ; 1991)$ nos brinda una explicación interesante al proponer que el término ushnu no se empleó en las crónicas prístinas del siglo XVI (o su símil quechua Usno, Osno, etc.), porque algunos cronistas estaban más interesados en describir una función específica del ushnu cuzqueño (por ejemplo libaciones, cultos religiosos, observaciones astronómicas, etc.) y por ello sus descripciones involucran solamente algunos de sus componentes (piedra, pila o canales donde se vierten líquidos o se observa el horizonte, por ejemplo). Eso, tal vez, pudo haber influido para dejar de lado el total de la descripción de las partes del ushnu del Cuzco, como las plataformas, por ejemplo, a «... modo edificios o a hechura de torres de muy hermoza cantería...» como señala Duviols (1984: 202 [1582]) al referirse a los de Vilcashuamán y Huánuco Pampa.

Se puede proponer otra alternativa y preguntar si los cronistas tempranos, más allá de sus intereses en describir la funcionalidad de los ushnus cuzqueños, ino estaban obviando mencionar grandes plataformas o hacer comparaciones con algún tipo de construcción como torre o edificio, para ayudarse en sus descripciones, porque estas características formales no eran de las magnitudes de Vilcashuamán o Huánuco Pampa? Es decir, i si los ushnus del Cuzco, descritos por Betanzos, Pedro Cieza de León, Pedro Pizarro, Anónimo, Cristóbal de Molina, Cristóbal de Albornoz y Bernabé Cobo, no fueron una gran plataforma o plataformas superpuestas como los ushnus localizados fuera del Cuzco sino solamente, como ellos lo señalan: grandes piedras con una pila y con canales?

A continuación se analiza un asentamiento pre Tahuantinsuyo, con reocupación inca, en el Cuzco y otros tres de filiación incaica, dos de ellos en el Cuzco y otro en el NW argentino (Catamarca), con la intención de ver si el registro arqueológico nos puede ayudar a dilucidar si las características formales que señalan los cronistas del siglo XVI sobre los ushnus del Cuzco pueden ser ciertas o no.

\section{2. Grandes rocas en asentamientos pre Tahuantinsuyo}

Prospecciones superficiales y excavaciones arqueológicas en el asentamiento arqueológico de Choquepuquio (cuenca de Lucre, en el extremo este del valle del Cuzco) (McEwan et al., 1995; 2005) han determinado su ocupación desde el Intermedio Temprano hasta el periodo colonial español (McEwan et al., 1995). En el sector A de Choquepukio, Kendall (1976: 97) tomó una muestra radiocarbónica de una viga de madera de los muros (695 \pm 59 a. P. [BM. 924]). El autor calibró esta viga con la curva ShCal 04 del programa OxCal (McCormac et al., 2004) lo que dio un rango medio (68,2 \%) de 1339 cal d. C. De esa manera, confirmó su ocupación durante el Intermedio Tardío, lo que ya estaba evidenciado mediante excavaciones y recolección de material cerámico en superficie (Killke) (McEwan et al., 2005).

En el sector A, en el patio de las estructuras A1 y A3, se localizan casi al centro afloramientos rocosos, uno en cada uno (ver fig. 3). El afloramiento rocoso de la estructura A1 presenta en su lado sur un pozo, o alberca, poco profundo revestido 


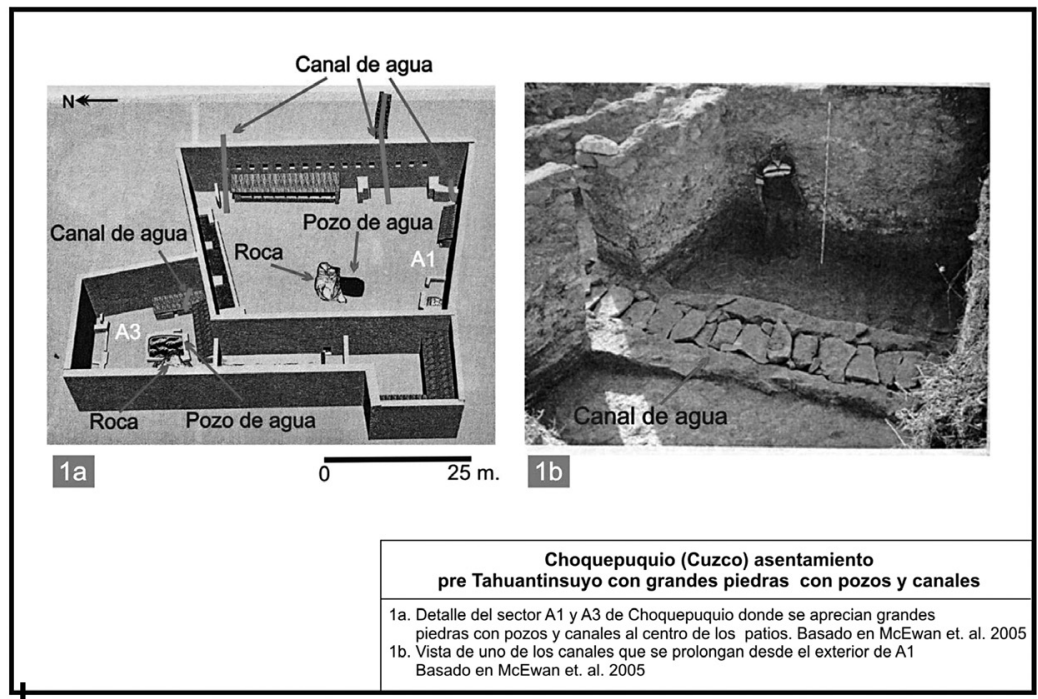

Figura 3 - Visión parcial del sector A del asentamiento pre Tahuantinsuyo de Choquepuquio (Cuzco)

Los subsectores A1 y A3 presentan grandes piedras o afloramientos rocosos con canales y pozos de características similares a las mencionadas en las crónicas sobre los ushnus del Cuzco. Lámina elaborada por Rodolfo Monteverde Sotil, 2010

con piedras, cuyo piso esta cuidadosamente revestido con losas de piedras fijadas con arcilla. Dicho pozo está conectado, por el lado oeste, con un canal. Según McEwan et al. $(1995 ;$ 2005) el agua circulaba por el canal, sobre el afloramiento y el pozo. Por su parte, el patio de la estructura A3 también presenta un afloramiento rocoso con un pozo o alberca revestida con piedras, que era alimentado con agua a través de canales. En estas dos estructuras se hubiera rendido culto al agua9 (así lo demuestran los hallazgos en la estructura A1 donde se encontraron gran cantidad de vasijas, botellas, platos, ollas y vasos del Intermedio Tardío, que habrían sido usados en festines y en cultos a los ancestros (se hallaron evidencias de entierro en muchos de los recintos del sector A) (McEwan et al., 2005).

\section{3. Grandes rocas en plazas de asentamientos Tahuantinsuyo}

A continuación se mencionan tres asentamientos Tahuantinsuyo, dos de ellos en el Cuzco y uno en la zona NW de Argentina, que podrían darnos algunas luces acerca de las características formales del ushnu de la plaza Haucaypata, Hurin Haucaypata o de otras del Cuzco en tiempos del incanato:

(1) Al noreste de la llacta cuzqueña, dentro del Parque Arqueológico de Sacsayhuaman, se encuentra Quenqo Grande, un inmenso roquedal tallado y

9 Al lado este del sitio hay un manantial que, tal vez, le da el nombre de Choquepukio: Choque $=$ oro y pukio= manantial (McEwan et al., 2005: 259). 
anexado a una plaza semicircular con muros que presentan vanos de acceso y hornacinas. En uno de los extremos de la plaza, cercano al roquedal, hay una gran roca de seis metros de altura (Ángles Várgas, 1990) sobre una suerte de pedestal o plataforma de planta rectangular de dos, probablemente tres, hiladas de sillar (ver fig. 4).

(2) En Quispeguanca, en el valle del Urubamba (Farrington, 1995), en el sector B existe una plaza de 205 m x 120 m, alrededor de la cual se organizan los edificios de ese sector. En su centro se encuentra localiza una gran roca alargada sin tallar de unos 2,6 $\mathrm{m} \times 4 \mathrm{~m}$. Cerca de esta pasa un canal de agua. Asimismo, a esta plaza ingresa un tramo de camino inca (Farrington) (ver fig. 4).

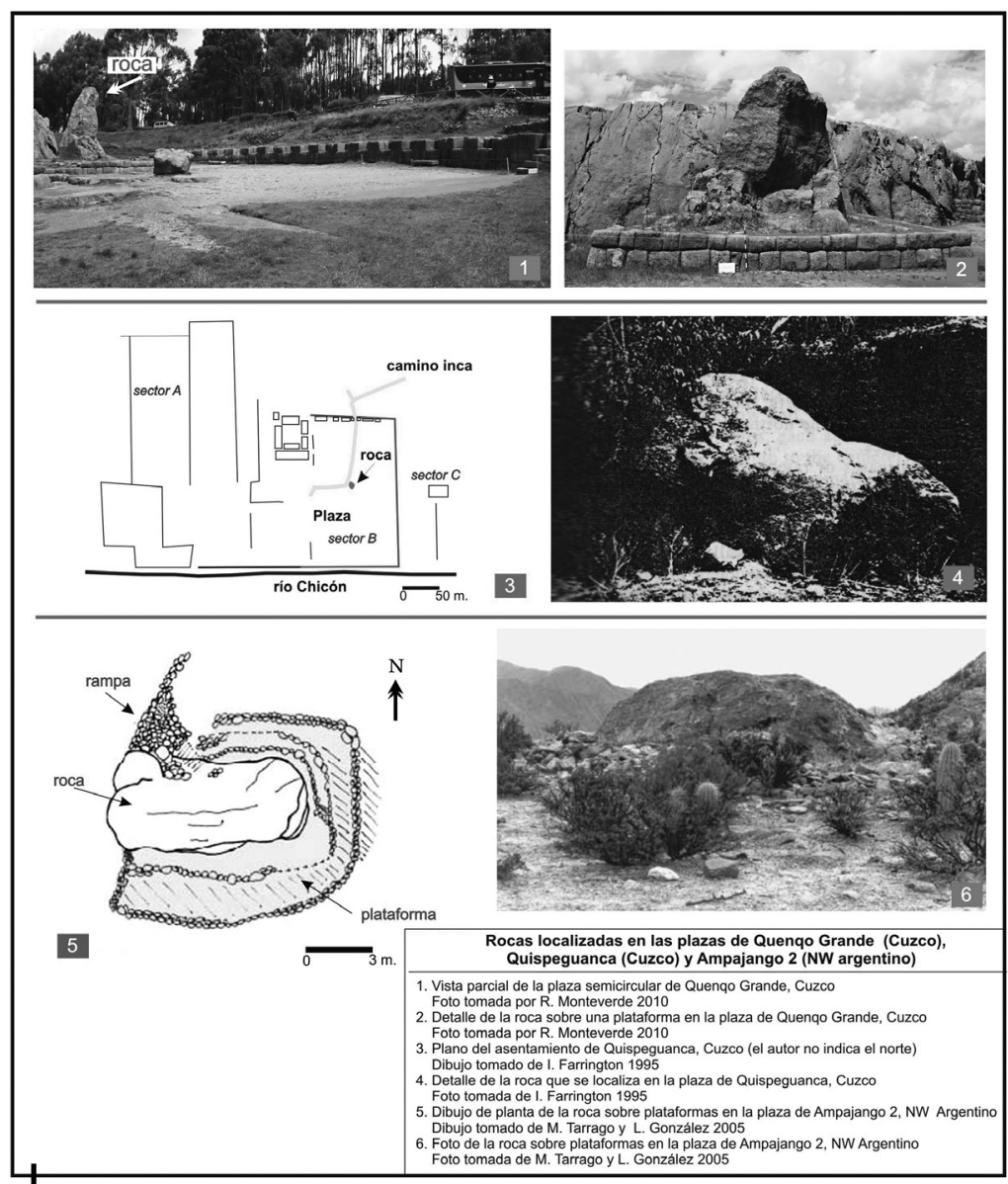

Figura 4 - Grandes rocas localizadas en tres plazas Tahuantinsuyo a las cuales, en algunos casos, se les han implementado plataformas, rampas y están asociadas a canales de agua

Lámina elaborada por Rodolfo Monteverde S. 2010 
(3) En Ampajango 2, valle de Yocavil, provincia de Catamarca, Argentina, en la plaza del sector IV existe una gran roca10 rodeada, en su parte inferior, de plataformas superpuestas y con una rampa o escalinata en uno de sus lados que permite acceder a la parte alta de la roca (Tarrago \& González, 2005) (ver fig. 4).

Debemos resaltar que:

- la roca de Quenqo Grande no ha sido propuesta como ushnu, razón por la cual, hasta ahora, hemos evitado discutir este tema;

- que la roca de Quispeguanca es solamente propuesta como ushnu más no analizada como tal por Farrington (1995);

- que la gran roca en Ampajango 2 sí es considerada como un ushnu (Tarrago \& González, 2005).

Aun así, se puede encontrar algunas recurrencias en ellas tres que hacen pensar en una intención tácita por parte del Tahuantinsuyo en relación a: (1) localizar una gran roca en una plaza (o viceversa implementar una plaza en torno a un afloramiento rocoso), en los tres casos y como señalan las crónicas respecto al ushnu del Haucaypata y Hurin Haucaypata; (2) por ende asignarle un rol público a las grandes piedras, en los tres casos y al igual que el ushnu del Haucaypata y Hurin Haucaypata y; (3) efectuar una implementación o adecuación cultural a las piedras o rocas (con pozos, canales y plataformas), no evidenciados en todas ellas, pero de manera similar como señalan las crónicas acerca del ushnu del Haucaypata por ejemplo.

Se encuentran presentes estas tres características ya desde épocas anteriores al Tahuantinsuyo, en el mismo valle del Cuzco (Choquepuquio) donde se implementaron, igualmente, grandes piedras con pozos y canales durante el Intermedio Tardío.

\section{USHNUS LOCALIZADOS EN ASENTAMIENTOS TAHUANTINSUYO FUERA DEL CUZCO}

Se han podido evidenciar ushnus en las cumbres o partes bajas de algunas montañas (Meddens et al., 2008; 2010; Cavero, 2009), asociados a la vera de la red vial inca (Cavero, 2009; Astuhuamán, 2008 respectivamente) y en diversos asentamientos Tahuantinsuyo del Perú y Sudamérica como en Pumpu, Junín (Matos, 1994); en Shincal de Quimivil, Catamarca-Argentina (Raffino et al., 1997); en Caxas, Aypate y Mitupampa, sierra de Piura (Astuhuamán, 1998); en Maucallacta, Arequipa (Presbítero et al., 2000-2001); en Curamba, Andahuaylas (Amorín \& Alarcón, 2001); en La Puruchuca, Huaycán de Pariachi y San Juan de Pariachi, en el valle del Rímac, Lima (Villacorta, 2003); en Huánuco Pampa,

10 En esta misma plaza existe otro peñasco o roca de menores dimensiones rodeado de una plataforma (Tarrago \& González, 2005). 
Huánuco (Pino, 2004; 2005; Bar Esquivel, 2006-200711) y en Piedra Angosta, valle de Mala-Cañete (Monteverde, 2008).

A continuación, en base a la evidencia arquitectónica y arqueológica de los ushnus mencionados en el párrafo superior, se va a analizar su localización dentro de la distribución espacial del asentamiento y sus características formales o arquitectónicas (plataformas, elementos de acceso, pozos y canales y tianas o asientos). Se analizarán y detallarán estas características hasta donde la evidencia arquitectónica y arqueológica lo permite. En efecto, muchos de estos ushnus no se han excavado sistemáticamente, se encuentran muy destruidos o han recibido inadecuados trabajos de restauración que han alterado su configuración original.

\section{1. Ushnus y plazas}

La organización espacial de los asentamientos Tahuantinsuyo estuvo regulada básicamente por una gran plaza localizada en su parte central, que en cierto modo determina la distribución de los edificios organizados alrededor de ella (ver figs. 5 y 6). Si los incas se asentaban en un territorio ya ocupado, reorganizaban el espacio diseñando nuevas plazas12 y construyendo infraestructuras de representación estatal como los ushnus, templos del Sol o acllahuasis.

Las plazas principales podían tener forma trapezoidal, rectangular o incluso irregular (ver figs. $5 ; 6 ; 7$ ), dependiendo de las características topográficas del lugar. Asimismo, las estructuras arquitectónicas también estaban organizadas en torno a plazas más pequeñas y/o canchas (espacio cercado con estructuras alrededor de un patio). Es precisamente dentro de las grandes plazas de los asentamientos Tahuantinsuyo donde encontramos localizados los ushnus, generalmente uno por asentamiento y uno por plaza. Pero salvo algunas excepciones pueden haber hasta dos ushnus en un mismo asentamiento. De ser así, uno de ellos se localiza en otra plaza o cancha mucho más pequeña, como en la plaza del Acllahuasi de Incahuasi (Hyslop, 1985) (ver fig. 6-10) o la cancha del Acllahuasi de Aypate (Astuhuamán, 1998) (ver fig. 5-2).

La presencia del ushnu en relación a la plaza principal (ver cuadro 2) va desde estar localizado en uno de sus bordes, tanto interno (ver figs. 5-2 y 5; 6-7 y 9) como externo (ver fig. 5-3), y al centro o casi al centro de ella (ver figs. 5-1 y $4 ; 6-6,8$ y 10). Asimismo, entra o pasa muy cercano a esta plaza un tramo del Capac Ñan (ver figs. 5-1, 2, 4 y 5; 6-6 y 8); a veces, pasa muy cerca del ushnu. Además, de esta plaza salen caminos internos que sirven para desplazarse dentro del asentamiento. Hemos notado que la intención de interrelacionar ushnus y

11 El Licenciado Alfredo Bar Esquivel fue el Director del Proyecto Arqueológico de Puesta en Valor del Ushnu de Huánuco Pampa 2006-2007. Este proyecto estuvo orientado a la restauración del muro oeste del ushnu y a la conservación preventiva del material arqueológico excavado por el Craig Morris en este sitio.

12 Ejemplo de ello podemos mencionar a la Puruchuca, asentamiento Tahuantinsuyo en el valle medio-bajo del Rímac donde existe un ushnu (Villacorta, 2003). 
Tahuantinsuyo: la arquitectura de los ushnus como espacios de libaciones y ofrendas líquidas

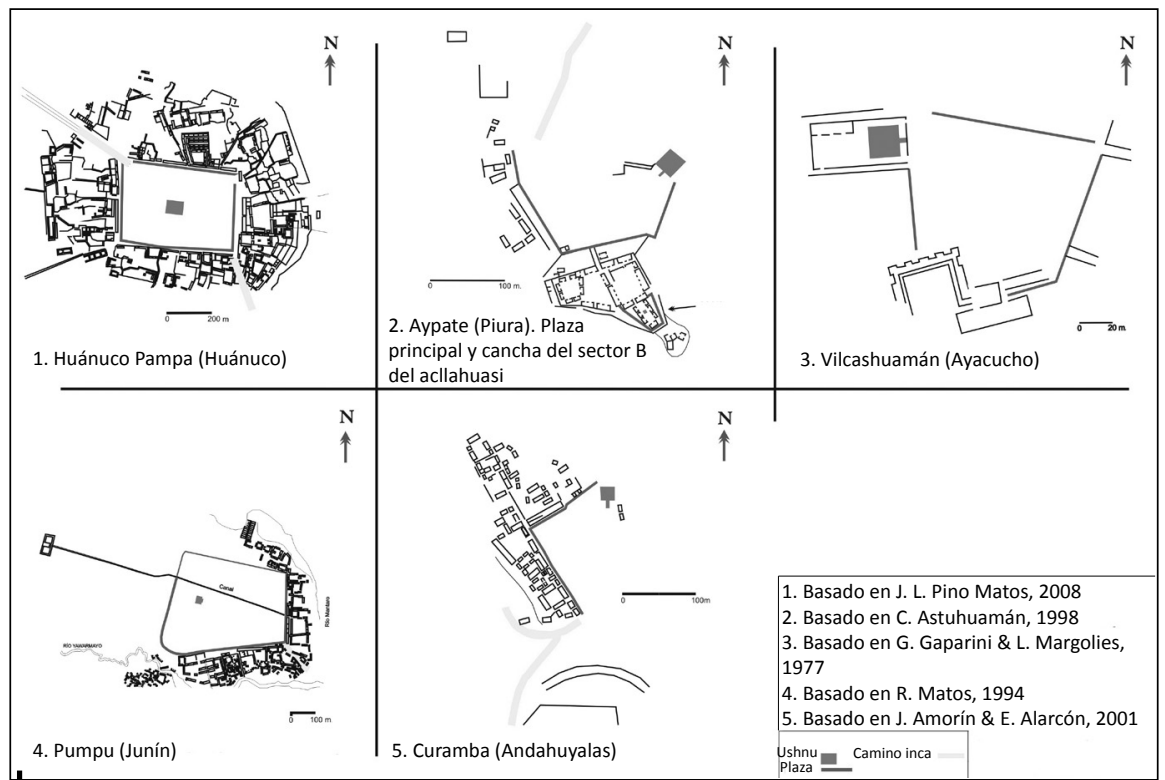

Figura 5 - Organización espacial de asentamientos Tahuantinsuyo fuera del Cuzco con ushnus en sus plazas principales

La red vial inca cruza algunas de estas plazas. Lámina diseñada por Rodolfo Monteverde S., 2010

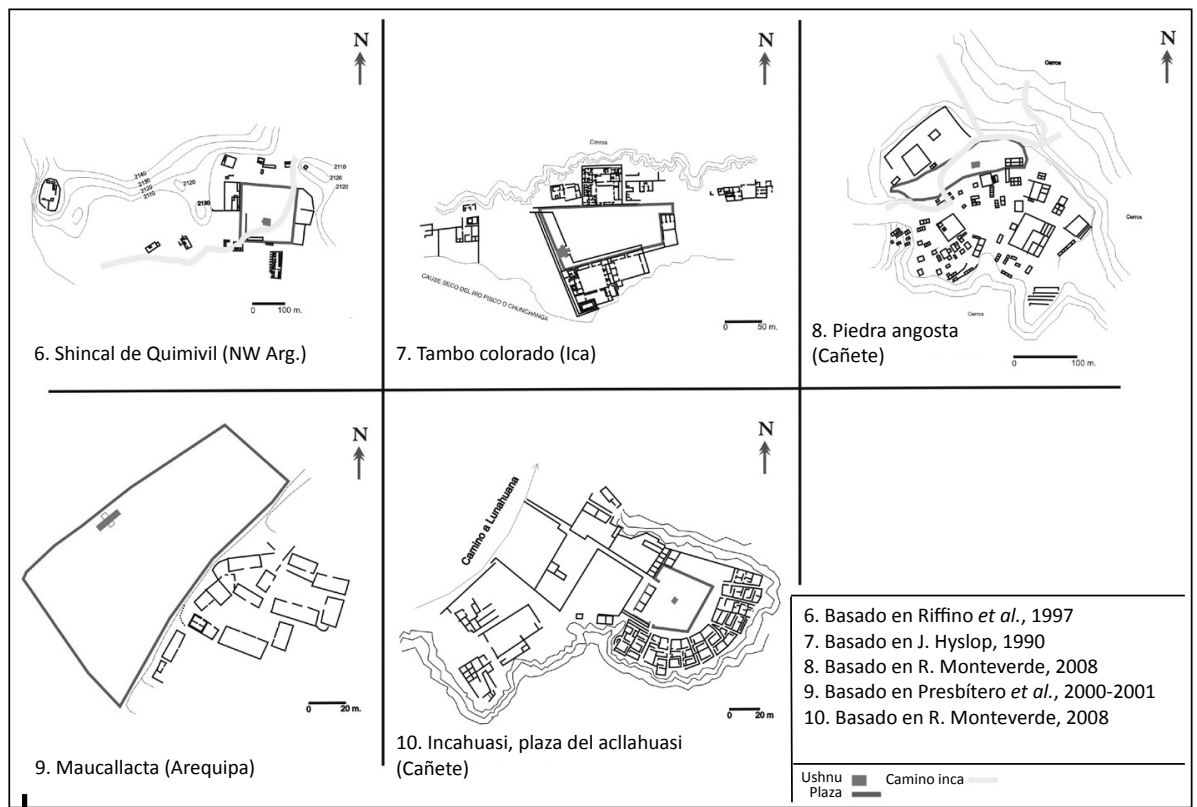

Figura 6 - Organización espacial de asentamientos Tahuantinsuyo fuera del Cuzco con ushnus en sus plazas principales

La red vial inca cruza algunas de estas plazas. Lámina diseñada por Rodolfo Monteverde S., 2010 


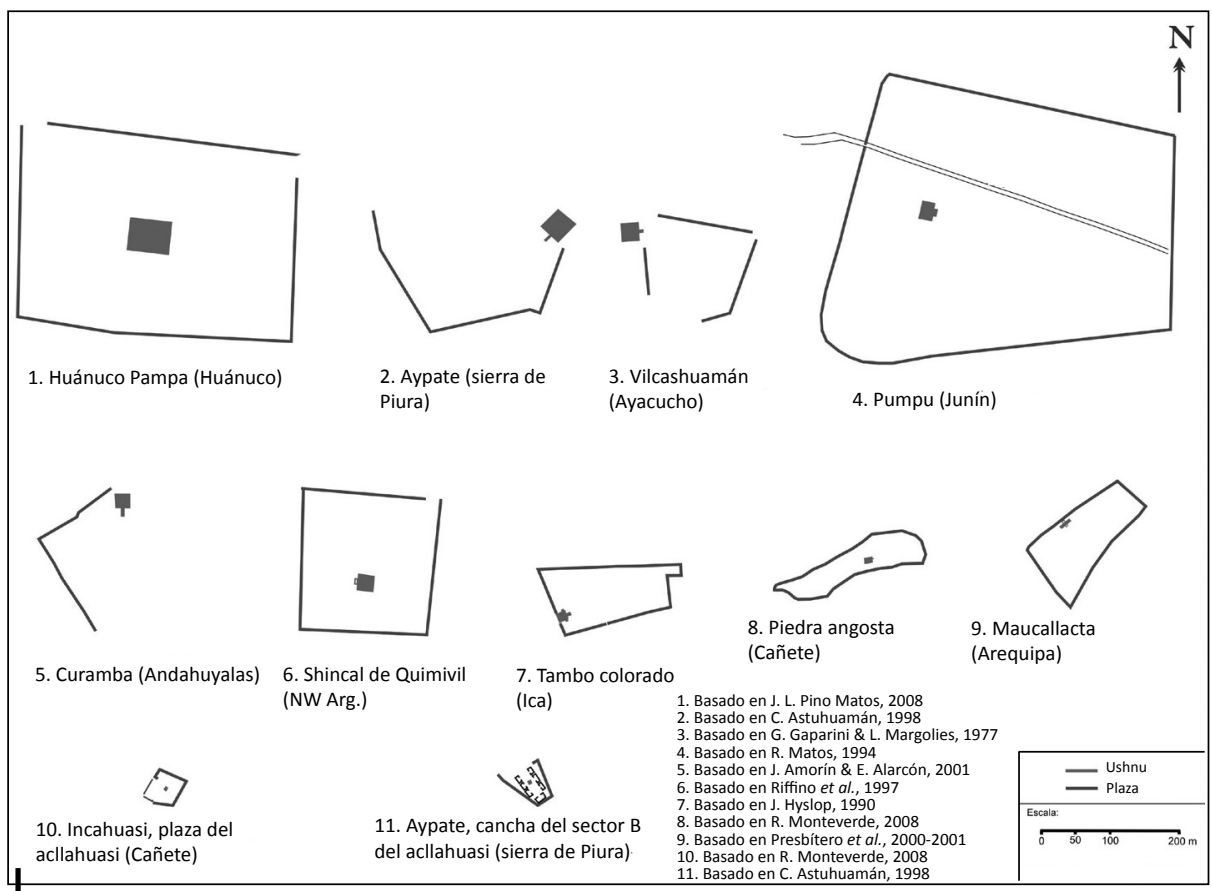

Figura 7 - Esquema a escala donde se comparan las dimensiones de plazas con ushnus en asentamientos Tahuantinsuyo fuera del Cuzco

Lámina elaborada por Rodolfo Monteverde S., 2010

plazas se evidencia en la orientación del lado principal del ushnu hacia la plaza misma. Precisamente en este lado hay vanos de acceso y escalinatas o rampas que permiten acceder desde el nivel del suelo de la plaza a la plataforma superior. Se detallará al respecto líneas más a delante.

\section{2. Ushnus y plataformas}

En las plazas principales de los asentamientos Tahuantinsuyo fuera del Cuzco existen ushnus a modo de una plataforma o plataformas superpuestas. Son de tamaños diversos, desde muy grandes a muy chicos, pero siempre de planta rectangular, cuadrangular o, en menor proporción, trapezoidales (ver fig. 9 y cuadro 2). El número de plataformas superpuestas puede ser una, dos, tres o hasta cuatro como Vilcashuamán, que es el ushnu más alto, pero no el de la plataforma inferior con planta más grande (ver figs. 8; 9 y cuadro 2). La plataforma inferior, como en Huánuco Pampa (ver cuadro 3), a veces sirvió para nivelar el nivel de la superficie de la plaza sobre la cual se iba a levantar el ushnu.

En algunos casos, si hay dos ushnus en un mismo asentamiento, uno de ellos es de menor tamaño y se localiza en una plaza o cancha igualmente de menores dimensiones y de acceso pedestre restringido. Es el caso de los Acllahuasi de 
Tahuantinsuyo: la arquitectura de los ushnus como espacios de libaciones y ofrendas líquidas

Cuadro 2 - Características de localización, orientación y arquitectónicas de ushnus localizados en asentamientos Tahuantinsuyo fuera del Cuzco, analizados en el presente artículo

Cuadro elaborado por Rodolfo Monteverde Soltil, 2010

\begin{tabular}{|c|c|c|c|c|c|c|}
\hline $\begin{array}{l}\text { Asentamiento } \\
\text { arqueológico }\end{array}$ & $\begin{array}{c}\text { Localización } \\
\text { del ushnu } \\
\text { en la plaza } \\
\text { principal }\end{array}$ & $\begin{array}{c}\text { Número de } \\
\text { plataformas } \\
\text { superpuestas } \\
\text { del ushnu }\end{array}$ & $\begin{array}{c}\text { Tipo de } \\
\text { planta de la } \\
\text { plataforma } \\
\text { inferior del } \\
\text { ushnu }\end{array}$ & $\begin{array}{c}\text { Dimensiones } \\
\text { de la } \\
\text { plataforma } \\
\text { inferior del } \\
\text { ushnu }\end{array}$ & $\begin{array}{c}\text { Materiales } \\
\text { y estilo de } \\
\text { construcción } \\
\text { de las } \\
\text { plataformas } \\
\text { del ushnu }\end{array}$ & $\begin{array}{l}\text { Orientación } \\
\text { /Lado de la } \\
\text { escalinata } \\
\text { (E) o rampa } \\
\text { (R) del } \\
\text { ushnu } \\
\end{array}$ \\
\hline $\begin{array}{l}\text { Huánuco Pampa, } \\
\text { Huánuco (Morris } \\
\text { \& Thompson, } \\
\text { 1985; Bar, 2009, } \\
\text { com. pers.) }\end{array}$ & Al centro & 3 & Rectangular & $45 \mathrm{~m} \times 32 \mathrm{~m}$ & $\begin{array}{l}\text { Piedra/ Inca } \\
\text { imperial }\end{array}$ & (E) Sur \\
\hline $\begin{array}{c}\text { Aypate, Piura } \\
\text { (Astuhuamán, } \\
\text { 1998) }\end{array}$ & $\begin{array}{l}\text { En el lado } \\
\text { este }\end{array}$ & 2 & Trapezoidal & $\begin{array}{c}44,9-34,6 \\
\mathrm{~m} \times 31.45- \\
31,83 \mathrm{~m}\end{array}$ & $\begin{array}{l}\text { Roca semi } \\
\text { canteada }\end{array}$ & $\begin{array}{l}\text { (E) SW / } \\
\text { (E) SE }\end{array}$ \\
\hline $\begin{array}{l}\text { Vilcashuamán, } \\
\text { Ayacucho } \\
\text { (Gasparini \& } \\
\text { Margolies, 1977; } \\
\text { Monteverde, } \\
\text { 2006, prospección } \\
\text { sin publicar) }\end{array}$ & $\begin{array}{l}\text { En el lado } \\
\text { oeste }\end{array}$ & 4 & Cuadrangular & $26 \mathrm{~m} \times 24 \mathrm{~m}$ & $\begin{array}{l}\text { Piedra/ Inca } \\
\text { imperial }\end{array}$ & (E) Este \\
\hline $\begin{array}{l}\text { Pumpu, Junín } \\
\text { (Matos, 1994) }\end{array}$ & $\begin{array}{l}\text { En el lado } \\
\text { este }\end{array}$ & 3 & Rectangular & $25 \mathrm{~m} \times 20 \mathrm{~m}$ & $\begin{array}{l}\text { Piedra/ Estilo } \\
\text { rústico }\end{array}$ & $\begin{array}{l}\text { (E) Este / (R) } \\
\text { Oeste }\end{array}$ \\
\hline $\begin{array}{c}\text { Curamba, } \\
\text { Andahuaylas } \\
\text { (Amorín \& } \\
\text { Alarcón, 2001) }\end{array}$ & En el lado NE & 3 & Cuadrada & $20 \mathrm{~m} \times 20 \mathrm{~m}$ & $\begin{array}{l}\text { Piedra/ Estilo } \\
\text { rústico }\end{array}$ & (E) Sur \\
\hline $\begin{array}{c}\text { El Shincal de } \\
\text { Quimivil, valle } \\
\text { de Hualfín-NW } \\
\text { Argentina (Raffino } \\
\text { et al., 1997) }\end{array}$ & Al centro & 1 & Cuadrangular & $16 \mathrm{~m} \times$ lado & $\begin{array}{l}\text { Piedra/ Estilo } \\
\text { rústico }\end{array}$ & (E) Oeste \\
\hline \begin{tabular}{|c|} 
Tambo Colorado, \\
Pisco-Ica \\
(Monteverde \\
2007, prospección \\
sin publicar; \\
2008)
\end{tabular} & $\begin{array}{l}\text { En el lado } \\
\text { oeste }\end{array}$ & 1 & Cuadrangular & $14 \mathrm{~m} \times 10 \mathrm{~m}$ & $\begin{array}{c}\text { Piedra y } \\
\text { adobe / Estilo } \\
\text { rústico }\end{array}$ & (R) NE \\
\hline $\begin{array}{l}\text { Piedra Angosta } \\
\text { o Aymará, valle } \\
\text { de Mala-Cañete } \\
\text { (Monteverde, } \\
\text { 2008) }\end{array}$ & Casi al centro & 1 & Rectangular & $\begin{array}{c}10,5 \mathrm{mx} \\
9,3 \mathrm{~m}\end{array}$ & $\begin{array}{l}\text { Piedra/ Estilo } \\
\text { rústico }\end{array}$ & SW \\
\hline \begin{tabular}{|c|} 
Maucallacta, \\
Arequipa \\
(Presbítero et al., \\
2000-2001) \\
\end{tabular} & En el lado NE & 1 & Rectangular & $11 \mathrm{~m} \times 7 \mathrm{~m}$ & $\begin{array}{c}\text { Piedra/ Inca } \\
\text { imperial/ } \\
\text { rústico }\end{array}$ & (E) SE \\
\hline $\begin{array}{c}\text { Incahuasi, } \\
\text { Cañete "plaza } \\
\text { del acllahuasi» } \\
\text { (Monteverde, } \\
\text { 2007, prospección } \\
\text { sin publicar; } \\
\text { 2008) }\end{array}$ & Al centro & 1 & Rectangular & $2,2 \mathrm{~m} \times 1,8 \mathrm{~m}$ & Adobe & $\begin{array}{c}\text { no tiene (R) } \\
\text { ni (E) / NE }\end{array}$ \\
\hline $\begin{array}{c}\text { Aypate, Piura } \\
\text { «cancha del sector } \\
\text { B del acllahuasi» } \\
\text { (Astuhuamán, } \\
\text { 1998) }\end{array}$ & Al centro & 1 & Rectangular & $1,3 \mathrm{~m} \times 1,1 \mathrm{~m}$ & Piedra & $\begin{array}{l}\text { No tiene (R) } \\
\text { ni (E) }\end{array}$ \\
\hline
\end{tabular}


Incahuasi y Aypate13 (Hyslop, 1985; Astuhuamán 1998, respectivamente). Estas dos estructuras de planta rectangular son de tamaño pequeño (ver cuadro 2), con

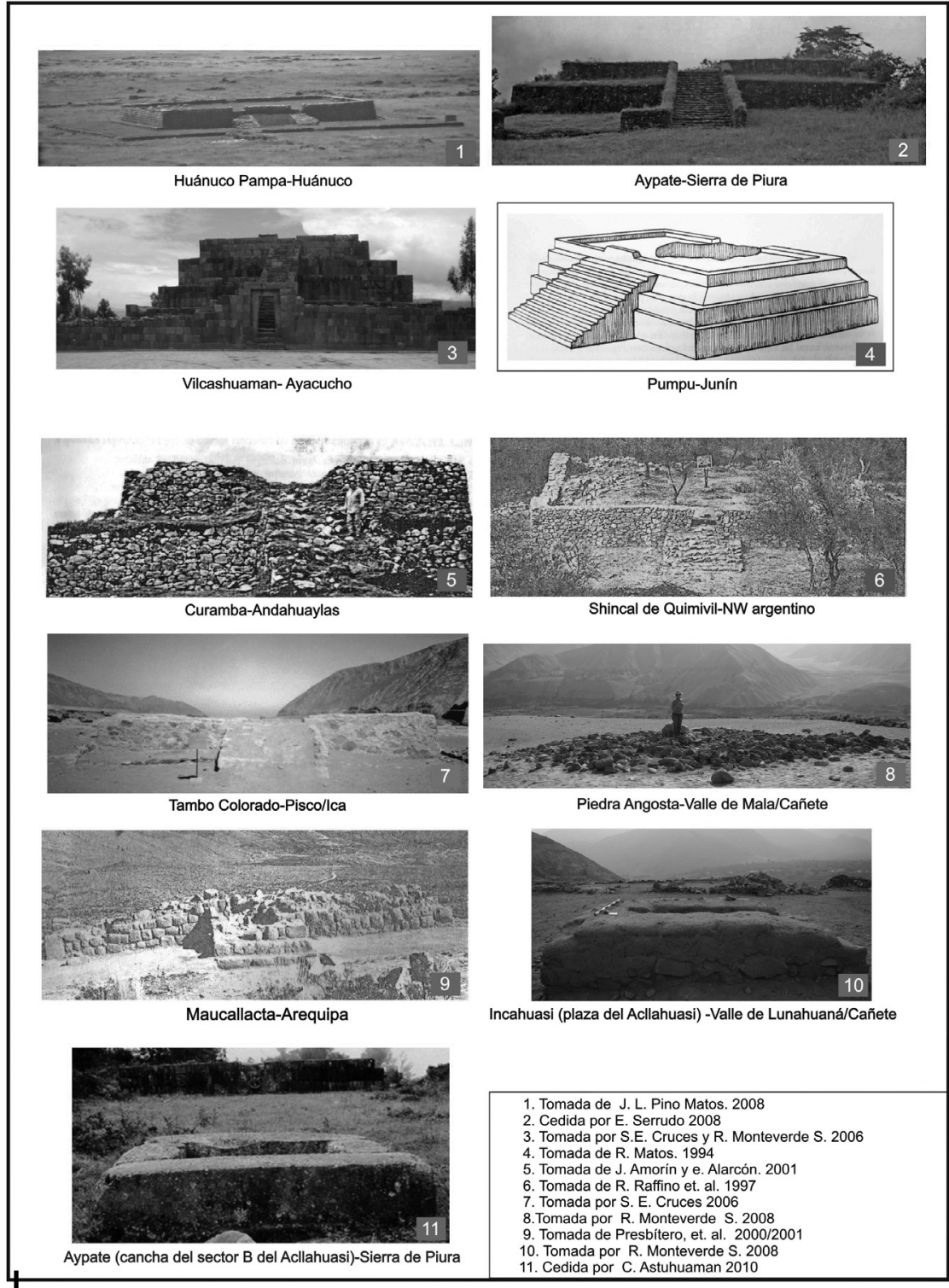

Figura 8 - Fotografías donde se puede apreciar la diversidad formal de los ushnus (dimensiones, factura y elementos constructivos)

Lámina elaborada por Rodolfo Monteverde S., 2010

13 La estratigrafía de las excavaciones de Polía Meconi (en Astuhuamán, 1998) ha demostrado que este ushnu corresponde al mismo periodo de construcción u ocupación incaica del lugar. 


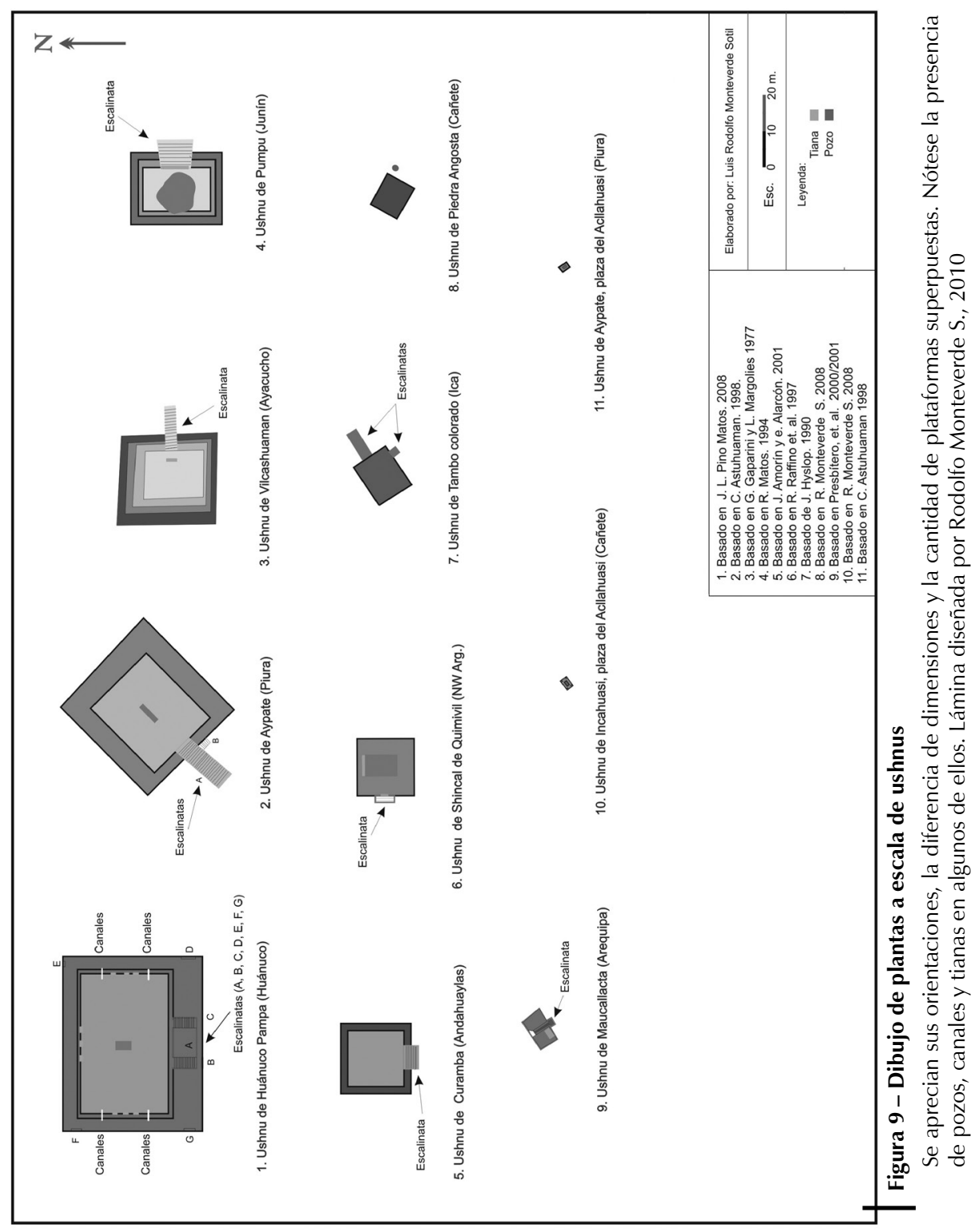


Cuadro 3 - Técnicas constructivas de ushnus localizados en asentamientos Tahuantinsuyo fuera del Cuzco Cuadro elaborado por Rodolfo Monteverde S., 2010

\begin{tabular}{|c|c|}
\hline $\begin{array}{l}\text { Asentamiento } \\
\text { arqueológico }\end{array}$ & Técnica constructiva del ushnu \\
\hline $\begin{array}{l}\text { Huánuco Pampa, } \\
\text { Huánuco (Morris \& } \\
\text { Thompson, 1985; Bar } \\
\text { com. pers., 2009) }\end{array}$ & $\begin{array}{l}\text { Solamente la plataforma superior presenta rocas de estilo imperial, con bloques } \\
\text { rectangulares unidos sin argamasa. Las dos plataformas inferiores y las escalinatas } \\
\text { pequeñas son de estilo rústico. Las rocas inferiores de las plataformas han sido } \\
\text { asentadas sobre una capa de arcilla compacta. }\end{array}$ \\
\hline $\begin{array}{c}\text { Aypate, Piura } \\
\text { (Astuhuamán, 1998) }\end{array}$ & $\begin{array}{c}\text { En las tres plataformas se empleó roca semicanteada de tamaño mediano y } \\
\text { pequeño. Se usó argamasa de barro. Se rellenaron los muros de contención del } \\
\text { ushnu con capas de roca y barro, sellándose con un piso de lajas de roca. }\end{array}$ \\
\hline $\begin{array}{l}\text { Vilcashuamán, Ayacucho } \\
\text { (González et al., 1996) }\end{array}$ & $\begin{array}{l}\text { Los muros de las plataformas están conformados por bloques de piedra acabados y } \\
\text { pulidos solo en una de sus caras, las que forman el paramento visible. La estructura } \\
\text { interna del ushnu está formada por cantos rodados y barro arcilloso. }\end{array}$ \\
\hline $\begin{array}{c}\text { Pumpu, Junín (Matos, } \\
\text { 1994) }\end{array}$ & $\begin{array}{l}\text { Simple en su construcción y rústico en su acabado. La técnica de edificación y } \\
\text { ornamentación de la mampostería no recibió mejor tratamiento, no hay diferencia } \\
\text { con el resto de edificios del lugar. Se emplearon generalmente piedras alargadas y } \\
\text { mortero de barro mezclado con paja. Probablemente se tarrajearon las paredes con } \\
\text { barro de color amarillo-marrón (este ushnu no fue excavado). }\end{array}$ \\
\hline $\begin{array}{c}\text { Curamba, Apurímac } \\
\text { (Amorín \& Alarcón, 2001) }\end{array}$ & De mampostería simple con piedras seleccionadas y argamasa de barro. \\
\hline $\begin{array}{c}\text { Shincal de Quimivil, NW } \\
\text { argentino (Raffino et al., } \\
\text { 1997) }\end{array}$ & $\begin{array}{l}\text { De aparejo murario rústico. En algunos casos las piedras fueron trabajadas con la } \\
\text { intención de imitar la cantería cuzqueña, pero no en todos los casos. Sus muros } \\
\text { son dobles con relleno interior de barro. Se rellenó la plataforma con sedimento } \\
\text { arcilloso traído del río Simbolar. }\end{array}$ \\
\hline $\begin{array}{l}\text { Piedra Angosta, } \\
\text { valle de Mala-Cañete } \\
\text { (Monteverde, 2008) }\end{array}$ & $\begin{array}{l}\text { Ha sido construido superponiendo gran cantidad de piedras semi ovaladas de } \\
\text { medianas dimensiones. Empleándose grandes rocas en la base. Estas piedras están } \\
\text { alternadas con argamasa de barro. }\end{array}$ \\
\hline $\begin{array}{l}\text { Maucallacta, Arequipa } \\
\text { (Presbítero et al., 2000- } \\
\text { 2001) }\end{array}$ & $\begin{array}{l}\text { Construido con piedras ajustadas con precisión, en la fachada se empleó } \\
\text { mampostería inca imperial. Se rellenó la plataforma con piedras sueltas y tierra. Fue } \\
\text { levantado sin cimientos directamente desde el suelo, probablemente no se terminó } \\
\text { su construcción. }\end{array}$ \\
\hline $\begin{array}{l}\text { Incahuasi } \ll \text { Plaza del } \\
\text { acllahuasi»», Cañete } \\
\text { (Hyslop, 1985; } \\
\text { Monteverde, 2006, } \\
\text { prospección sin publicar) }\end{array}$ & $\begin{array}{c}\text { Estructura construida en base a } 4 \text { cuerpos o secciones de muro de pequeñas } \\
\text { dimensiones, de regulares dimensiones de estilo inca (según Hyslop, 1985) que, } \\
\text { unidos en sus extremos, constituyen las } 4 \text { paredes del ushnu, dejando así, en } \\
\text { la parte central un espacio vacío. Hoy muy está destruida en uno de sus lados } \\
\text { que le da una apariencia de planta en U. Presenta una depresión en las esquinas } \\
\text { superiores. }\end{array}$ \\
\hline $\begin{array}{l}\text { Aypate, «cancha del } \\
\text { Sector B del acllahuasi», } \\
\text { Piura (Astuhuamán, 1998) }\end{array}$ & $\begin{array}{l}\text { Estructura constituida por } 4 \text { bloques paralepípedos de granito rosado, de } 0,32 \mathrm{~m} \\
\text { de espesor y } 0,60 \mathrm{~m} \text { de altura que, al ser unidos, formaron un espacio abierto en } \\
\text { su parte central. }\end{array}$ \\
\hline
\end{tabular}

un promedio de 1,5 m por lado, y con alturas que no superan el metro. Ambos han sido construidos juntando cuatro grandes bloques de roca14 (Aypate) o cuatro muros compuestos por rocas pequeñas recubiertas con barro (Incahuasi) (ver figs. 8-10 y 11; 9-10 y 11; 10; 11). Formando así un cuerpo rectangular sólido de

14 Los cuatro bloques de piedra han sido colocados sobre un bloque de piedra que sirve de base (Polía Meconi, en Astuhuamán, 1998). 


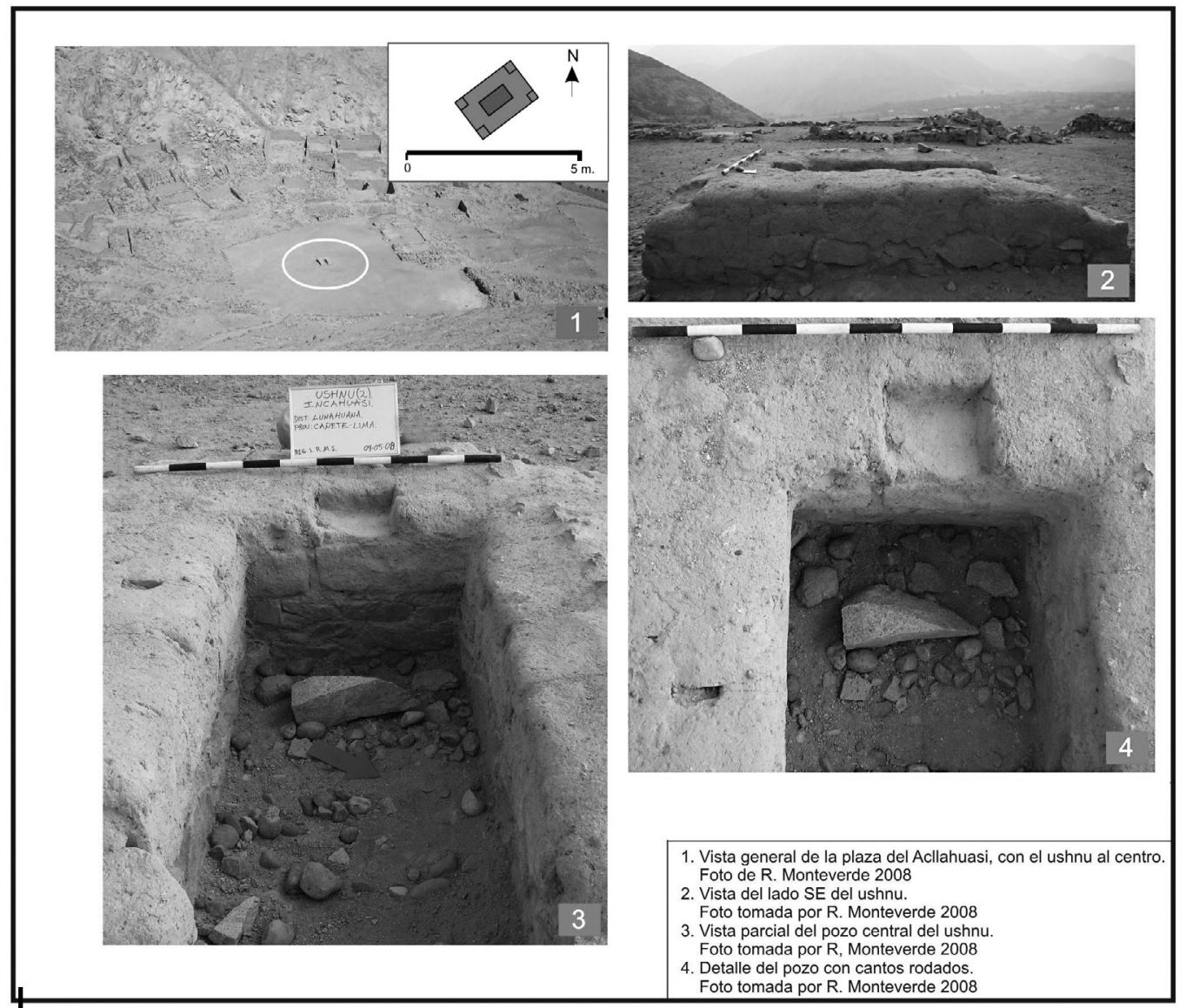

Figura 10 - Localización central del ushnu de Incahuasi, plaza del Acllahuasi

Se puede apreciar la presencia de un pozo de planta rectangular formado por las paredes de este ushnu, el cual presenta cantos rodados en su interior. Lámina diseñada por Rodolfo Monteverde S., 2010

paredes cuyo espesor es menor a un metro y que, debido a la unión de estos cuatro lados, tiene un espacio central de planta rectangular (ver cuadro 4). Sobre este espacio central hablaremos en el acápite de los pozos y canales en los ushnus. Se puede constatar que hay una gran flexibilidad en lo que respecta a las dimensiones de la planta y la altura del ushnu. También varía la técnica utilizada en su construcción, ya que puede ir desde el empleo del sillar de estilo inca imperial sin argamasa como Vilcashuamán (ver fig. 8-3 y cuadro 2); el empleo, al mismo tiempo, de sillar estilo inca imperial y rústico como Huánuco Pampa y Maucallacta (ver fig. 8-9 y cuadros 2 y 3); o solamente el uso de piedra semicanteada dispuesta a modo de muros pirqueados como Pumpu (ver fig. 8-4 y cuadros 2 y 3). En términos generales son pocos los ushnus de aparejo murario estilo imperial, siendo en la mayoría de los casos de aparejo de factura rústica o sencilla. En el caso de la costa, como en La Puruchuca, San Juan de Pariachi y Huaycán de Pariachi se empleó el adobe en la construcción de los ushnus (Villacorta, 2003). 





Cuadro 4 - Características arquitectónicas y de localización de pozos y canales evidenciados en los ushnus, donde resalta la presencia de cantos rodados en prácticamente todos ellos. Cuadro elaborado por Rodolfo Monteverde S. 2010

\begin{tabular}{|c|c|c|c|c|}
\hline $\begin{array}{l}\text { Asentamiento } \\
\text { arqueológico }\end{array}$ & $\begin{array}{l}\text { Canal } \\
\text { del } \\
\text { ushnu }\end{array}$ & $\begin{array}{c}\text { Pozo del } \\
\text { ushnu }\end{array}$ & Características del canal y pozo del ushnu & $\begin{array}{l}\text { Localización } \\
\text { del Pozo (P) } \\
\text { o canal }(C) \\
\text { en relación al } \\
\text { ushnu }\end{array}$ \\
\hline $\begin{array}{l}\text { Huánuco } \\
\text { Pampa, } \\
\text { Huánuco (Pino, } \\
\text { 2008) }\end{array}$ & Sí & Sí & $\begin{array}{c}\text { De planta rectangular, de pequeñas dimensiones y } \\
\text { de poca profundidad, presenta en el piso interno } \\
\text { la presencia de gran cantidad de pequeñas piedras } \\
\text { ovaladas. }\end{array}$ & $\begin{array}{l}\text { (P) En la parte } \\
\text { central de la } \\
\text { plataforma } \\
\text { superior. (C) } \\
\text { salen por los } \\
\text { extremos de } \\
\text { la plataforma } \\
\text { superior }\end{array}$ \\
\hline $\begin{array}{c}\text { Aypate, Piura } \\
\text { (Astuhuamán, } \\
\text { 1998) }\end{array}$ & $?$ & Sí & $\begin{array}{l}\text { Estructura semi hundida (6,55 m de largo, } 2,05 \mathrm{~m} \\
\text { de ancho y } 0,85 \mathrm{~cm} \text { de altura), definida por bloques } \\
\text { de roca, tiene planta rectangular y orientación SW- } \\
\text { NE. Internamente no se aprecia piso superficial. Se } \\
\text { emplearon bloques de roca de tamaño mediano y } \\
\text { de forma cúbica o prismática y argamasa de barro. } \\
\text { Polía (citado por Astuhuamán) menciona que se } \\
\text { encontraron varias piedras redondeadas amontonadas } \\
\text { en un mismo punto, las cuales fueron traídas del cauce } \\
\text { del río del valle. }\end{array}$ & $\begin{array}{l}\text { (P) En la parte } \\
\text { central de la } \\
\text { plataforma } \\
\text { superior }\end{array}$ \\
\hline $\begin{array}{l}\text { Pumpu, Junín } \\
\text { (Matos, 1994) }\end{array}$ & Sí & Sí & $\begin{array}{c}\text { Es una depresión en el lado oeste de la plataforma } \\
\text { superior, de borde irregular y profundidad no mayor } \\
\text { a los } 0,80 \mathrm{~cm} \text {. Rellenado hasta cierta altura hasta } \\
\text { con pequeños cantos rodados, los cuales miden en } \\
\text { promedio entre } 0,10 \text { y } 0,15 \mathrm{~cm} \text { de diámetro y } 150 \mathrm{gr} \\
\text { de peso. El canal de agua cruza la plaza y pasa muy } \\
\text { cerca al ushnu }\end{array}$ & $\begin{array}{l}\text { (P) Hacia el } \\
\text { lado oeste de } \\
\text { la plataforma } \\
\text { superior. }(\mathrm{C}) \\
\text { pasa cerca al } \\
\text { ushnu }\end{array}$ \\
\hline $\begin{array}{c}\text { Shincal de } \\
\text { Quimivil, } \\
\text { NW argentino } \\
\text { (Raffino et al., } \\
\text { 1997) }\end{array}$ & No & Sí & $\begin{array}{l}\text { A } 0,80 \mathrm{~cm} \text { por debajo de la superficie del ushnu, se } \\
\text { construyó un piso empedrado, formado por miles } \\
\text { de guijarros traídos del río Simbolar localizado a } 200 \\
\text { metros de distancia. Por debajo del empedrado el } \\
\text { suelo fue consolidado con arcilla para darle mayor } \\
\text { consistencia }\end{array}$ & $\begin{array}{l}\text { (P) Casi al } \\
\text { centro de la } \\
\text { plataforma } \\
\text { superior }\end{array}$ \\
\hline $\begin{array}{l}\text { Piedra } \\
\text { Angosta, } \\
\text { Mala-Cañete } \\
\text { (Monteverde, } \\
\text { 2008) }\end{array}$ & No & Sí & $\begin{array}{l}\text { Estructura semi circular de } 0,70 \mathrm{~cm} \text { de diámetro y } \\
0,30 \mathrm{~cm} \text { de profundidad. Los bordes están constituidos } \\
\text { por piedras de pequeñas dimensiones. }\end{array}$ & $\begin{array}{l}\text { (P) Al } \\
\text { frente de la } \\
\text { plataforma a } \\
\text { dos metros de } \\
\text { distancia }\end{array}$ \\
\hline $\begin{array}{c}\text { Incahuasi } \\
\text { «plaza del } \\
\text { Acllahuasi» } \\
\text { (Hyslop, 1985; } \\
\text { Monteverde, } \\
2007, \\
\text { prospección, } \\
\text { sin publicar) } \\
\end{array}$ & No & Sí & $\begin{array}{l}\text { Este ushnu presenta en su parte central un pozo, } \\
\text { formado por la unión de los cuatro bloques de } \\
\text { muro, de planta rectangular que tiene menos de } 1 \\
\text { m de profundidad. En el piso de la parte interna se } \\
\text { evidenciaron escasos cantos rodados de color negro } \\
\text { que habrían rellenado, según Hyslop (1985), el interior } \\
\text { de la estructura. El autor pudo apreciar también dichos } \\
\text { cantos rodados el año } 2008 . \\
\end{array}$ & $\begin{array}{l}\text { (P) En la parte } \\
\text { central de la } \\
\text { estructura }\end{array}$ \\
\hline $\begin{array}{l}\text { Aypate, «Plaza } \\
\text { del sector B» } \\
\text { del Acllahuasi, } \\
\text { Piura } \\
\text { (Astuhuamán, } \\
\text { 1998) }\end{array}$ & Sí & Sí & $\begin{array}{l}\text { En la parte inferior e interna del pozo central de } \\
\text { la estructura, que tiene } 0,60 \text { m de profundidad y } \\
\text { que está formado por la unión de los } 4 \text { bloques de } \\
\text { piedra, hay un bloque de granito con una acanaladura } \\
\text { que desemboca en la canaleta externa subterránea } \\
\text { recubierta por lajas de roca, encima de las cuales se } \\
\text { hallaron gran cantidad de canto rodado, encontrados } \\
\text { en la superficie del suelo actual. }\end{array}$ & $\begin{array}{l}\text { (P) En la parte } \\
\text { central de la } \\
\text { estructura. } \\
\text { (C) sale de } \\
\text { la parte } \\
\text { inferior de la } \\
\text { estructura }\end{array}$ \\
\hline
\end{tabular}


Finalmente, mencionaremos que excavaciones arqueológicas realizadas en algunos ushnus han permitido saber que estas plataformas fueron rellenadas, por ejemplo, con sedimento arcilloso traído desde el río (Shincal de Quimivil), con rocas y barro sellado con una capa de lajas de roca (Aypate) o con piedras sueltas y barro (Vilcashuamán o Maucallacta).

\section{3. Elementos de acceso al ushnu (escalinatas o rampas y vanos)}

Ya se ha comentado que las escalinatas (ver cuadros 2 y 5), se prolongan desde el nivel del suelo de la plaza y se encuentran en la parte central y frontal del lado del ushnu que da a ella (ver fig. 8). Casi siempre es una sola gran escalinata por ushnu, pero puede darse el caso de tener una mucho más pequeña anexada a la escalinata más grande como en Aypate (ver figs. 9-2 y 12-2) o puede estar independiente y adosada a uno de los lados laterales del ushnu como en Tambo Colorado (ver fig. 9-7). Incluso la plataforma inferior puede presentar pequeñas escalinatas en sus bordes pero que no comunican directamente con la plataforma superior como en Huánuco Pampa (ver fig. 9-1), ya que la más grande lo hace. En todo caso estas pequeñas escalinatas sirven de complemento a la más grande.

Además, hay ushnus que, aparte de la escalinata frontal y principal, cuentan con una rampa en su lado posterior como es el caso de Pumpu que habría servido para descender del ushnu (Matos, 1994). Mientras que en el caso de los demás ushnus, tanto la subida como el descenso de la plataforma superior habría sido por la misma escalinata frontal. Asimismo, si el ushnnu es de planta rectangular, se colocan usualmente, en uno de los dos lados más largos, las escalinatas o rampas y los vanos de acceso al ushnu (típico en la arquitectura incaica, por ejemplo en las kallankas) (ver figs. 8; 9).

Estas grandes escalinatas 15 o rampas en los ushnus siempre conducen directamente a la plataforma superior, es decir, no van, de ser el caso, a la plataforma intermedia o penúltima (ver fig. 8). Generalmente las gradas que componen los peldaños de las escalinatas son lajas de piedras plana. La altura y extensión de la escalinata varían dependiendo de las dimensiones y volumen del ushnu. Algunas escalinatas presentan muros en sus lados delimitando así los peldaños como en Aypate (ver fig. 8-2 y cuadro 5). Además, Ilama la atención que las escalinatas o rampas de los ushnus no son angostas; es decir, casi en la mayoría, fácilmente podrían ascender o descender más de una persona a la vez.

Hay un solo vano por ushnu, generalmente trapezoidal (ver cuadro 5). Raramente pueden alcanzar hasta dos, como en Huánuco Pampa. En este caso se encuentran

15 En el caso de la costa, valle del Rímac (Villacorta, 2003), específicamente en La Puruchuca, la escalinata fue reemplazada por una rampa, pero igualmente ésta se prolonga desde el nivel del suelo de la plaza hasta la parte superior de la uniplataforma, y tanto la rampa como el frontis del ushnu están orientados hacia la plaza del asentamiento. Sin embargo no se han evidenciado vanos de acceso en la plataforma superior. 
Tahuantinsuyo: la arquitectura de los ushnus como espacios de libaciones y ofrendas líquidas

Cuadro 5 - Elementos de acceso (tianas y escalinatas) que conducen a la plataforma superior de algunos de los ushnus

Cuadro elaborado por Rodolfo Monteverde S. 2010

\begin{tabular}{|c|c|}
\hline $\begin{array}{l}\text { Asentamiento } \\
\text { arqueológico }\end{array}$ & Elementos de acceso al ushnu (escalinatas y vanos) \\
\hline $\begin{array}{l}\text { Huánuco Pampa, } \\
\text { Huánuco (Bar, com. } \\
\text { pers. 2009) }\end{array}$ & $\begin{array}{l}\text { Una amplia escalinata que conduce desde el nivel del piso de la plaza a la parte superior } \\
\text { del ushnu se localiza en el frontis principal y fiestá orientada hacia la plaza. Presenta dos } \\
\text { vanos de acceso en la parte superior. Se emplearon piedras planas para hacer las gradas. } \\
\text { Estas han sido colocadas sobre grandes piedras irregulares asentados sobre arcilla fina. }\end{array}$ \\
\hline $\begin{array}{c}\text { Aypate, Piura } \\
\text { (Astuhuamán, 1998) }\end{array}$ & $\begin{array}{l}\text { Una gran escalinata, de } 24 \text { peldaños, flanqueada por un borde, que conducen desde el } \\
\text { nivel del piso de la plaza a la plataforma superior, se localiza del lado del ushnu que da a } \\
\text { la plaza. A ella se une una pequeña escalinata que conduce desde el nivel del suelo a la } \\
\text { escalinata mayor en la cual se apoya. Ambas escalinatas han sido construidas con lajas } \\
\text { de piedras de tamaño mediano. En sus bordes se empleó roca semi canteada. }\end{array}$ \\
\hline $\begin{array}{l}\text { Pumpu, Junín } \\
\text { (Matos, 1994) }\end{array}$ & $\begin{array}{c}\text { Existe una escalinata en el frontis principal del ushnu y una rampa en el lado opuesto. La } \\
\text { escalinata, va desde le nivel del piso de la plaza hacia la plataforma superior y se orienta } \\
\text { hacia la plaza. Tiene } 9 \mathrm{~m} \text { de ancho y con una proyección hacia delante de } 5,50 \mathrm{~m} \text {. Fue } \\
\text { construida exactamente en la parte media del muro frontal. Tiene un ángulo de inclinación } \\
\text { de } 45 \text { grados. Tiene } 12 \text { peldaños de lajas de piedra blanca muy bien diseñados y } \\
\text { trabajados y con medidas distintas entre ellos. }\end{array}$ \\
\hline $\begin{array}{l}\text { Curamba, Apurímac } \\
\text { (Amorín \& Alarcón, } \\
\text { 2001) }\end{array}$ & $\begin{array}{l}\text { En una foto del ushnu antes de su restauración se observa una escalinata con muros } \\
\text { laterales que conduce desde el nivel del piso de la plaza a la plataforma superior donde } \\
\text { hay un vano de acceso. La escalinata está orientada hacia la plaza. }\end{array}$ \\
\hline $\begin{array}{l}\text { Shincal de Quimivil, } \\
\text { NW argentino } \\
\text { (Raffino et al., 1997) }\end{array}$ & $\begin{array}{l}\text { Escalinata de piedra, localizada en la parte central del frontis que da a la plaza. Tiene } 9 \\
\text { peldaños que conducen desde el nivel de la plaza a un vano trapezoidal colocado a la } \\
\text { entrada de la plataforma superior. }\end{array}$ \\
\hline $\begin{array}{l}\text { Maucallacta, } \\
\text { Arequipa (Presbítero } \\
\text { et al. 2000-2001) }\end{array}$ & $\begin{array}{c}\text { Escalinata de piedra de } 3 \text { peldaños y un vano de acceso de } 1 \text { metro de ancho en el frontis } \\
\text { del ushnu. }\end{array}$ \\
\hline
\end{tabular}

a cada extremo del ancho superior de la escalinata mayor (ver figs. 8-1; 9-1; 12 1). Es recurrente que el vano se halla siempre en la parte central superior de la escalinata y sirve como umbral comunicador entre ésta y la plataforma superior del ushnu (ver figs. 8-2, 3 y 6; 12-3 y 4). Pero no siempre los ushnus de gran tamaño presentan vano al igual que los de menor tamaño. En estos casos la escalinata desemboca directamente a la plataforma superior (ver fig. 8-7 y cuadro 5).

Finalmente se quiere agregar que las escalinatas presentes en los ushnus fueron completamente funcionales; en el caso que no se les requerían, debido a que el ushnu era pequeño, no se le construyó. Ejemplo de ello son los ushnus de los Acllahuasis de Incahuasi y Aypate ya que ninguno de ellos sobrepasa el metro de altura ni los dos metros de diámetro (ver figs. 8-10 y 11; 9-10 y 11 y cuadro 2). 


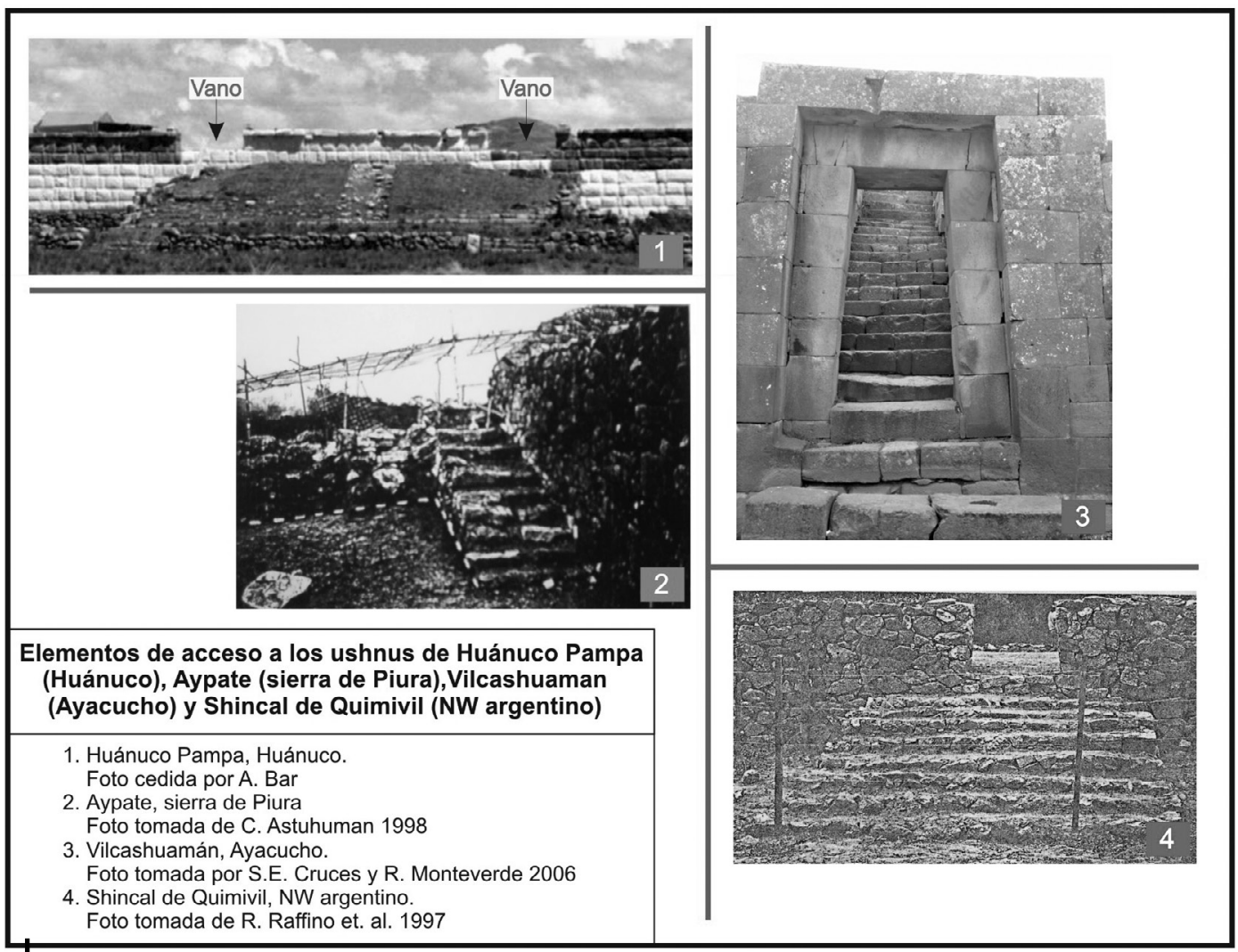

Figura 12 - Algunos ejemplos de vanos y escalinatas que conducen a la plataforma superior del ushnu

Lámina diseñada por Rodolfo Monteverde S., 2010

\section{4. Pozos y canales en los ushnus}

En lo que respecta a pozos y canales en los ushnus éstos no fueron analizados por John Hyslop (1990: 72) en su libro The Inka Settlement planning, porque desconocía sus existencias. Al respecto escribe:

«... where archaeologist have observed platforms, but no stone, basin, or drain. Only when ushnu platforms are excaved to see if they are equipped with drains will more be known...».

Hoy en día, gracias al aporte de diversas publicaciones arqueológicas, se puede afirmar que los ushnus se implementaron con estos elementos. Obviamente existen algunas diferencias, pero se mantienen ciertas recurrencias.

La mayor cantidad de pozos y canales, asociados entre ellos, se han evidenciado en la plataforma superior y central del ushnu (ver fig. 9 y cuadro 4). En algunos casos este pozo puede ser de grandes dimensiones como en Pumpu y Shincal de Quimivil (ver fig. 9-4 y 6) y, con mayor recurrencia, de escasas dimensiones 
como en Huánuco Pampa y Aypate (ver fig. 9-1 y 2). Son de poca profundidad (menos de 1 metro), de planta rectangular. Algunos presentan un pequeño muro en el borde de la superficie que los rodea y, en muchos casos, se han hallado gran cantidad de cantos rodados formando el piso del pozo y/o dentro o alrededor de él. Ese es el caso en Huánuco Pampa, Pumpu, Shincal de Quimivil, Aypate y para los ushnus del Acllahuasi de Incahuasi y Aypate (ver figs. 13; 10; 11 y cuadro 4).

Pero en algunos casos el pozo no era un elemento construido en la plataforma superior del ushnu sino que el cuerpo del ushnu mismo originaba el pozo. Tal es el caso de los ushnus del Acllahuasi de Incahuasi y Aypate (ver figs. 10; 11 y cuadro 4). En efecto, los cuatro muros que los conforman, dispuestos uno a cada lado, al momento de juntarse por sus extremos originaron un rectángulo en cuyo centro quedaba un espacio abierto de planta rectangular: el pozo del ushnu.

En lo que respecta a pozos y ushnus, se registra un caso peculiar en Piedra Angosta, valle de Mala-Cañete (Monteverde, 2008), donde el único ushnu del asentamiento presenta un pozo circular, no encima de la uniplataforma sino fuera de ella a escasos dos metros de distancia de su lado NE. Este pozo de poca profundidad, al igual que los mencionados anteriormente, fue construido cavando el suelo y delimitándolo con la disposición de piedras en sus bordes internos (ver figs. 8-8; $13-2 a$ y $2 b$ y cuadro 4$)$.

Pero no llama la atención que los pozos se hallen fuera del ushnu, puesto que los canales también pueden pasar fuera, aunque muy cerca de los ushnus como en Pumpu (Matos, 1994) (ver fig. 7-4). Hay que recordar además el caso de Quispeguanca en Cuzco (Farrington, 1995) (ver fig. 4-3). Probablemente estos canales que cruzan la plaza principal se comunican con uno más pequeño que saldría del ushnu. Recordemos que Matos (1994) no excavó en el ushnu de Pumpu (debido a su muy mal estado de conservación (com. pers., 2010), así que no hay que descartar la posibilidad.

En el caso específico del ushnu de Huánuco Pampa (Bar, 2009, com. pers.; Pino, 2008 y 2010, com. pers.) cuatro canales salen de la parte alta, dos por el lado este y dos por el oeste, de la plataforma superior en donde se localiza, en la parte central, el pozo (ver fig. 9-1 y cuadro 4).

Mientras que en el ushnu del Acllahuasi de Aypate (Polía Meconi, en Astuhuamán, 199816) (ver fig. 11-4 y cuadro 4), existe una acanaladura, en la parte central de la roca sobre la cual se levantan los cuatro bloques de piedras que forman el ushnu. Desde esta acanaladura se prolonga un canalito, asentado sobre una capa compacta de arcilla apisonada, conformado por dos piedras paralepípedas que forman sus lados. Sobre estas dos piedras se han colocado otras dos piedras irregulares, a modo de cobertor. Es sobre estas que Polía (in Astuhuamán, 1998) halló gran cantidad de canto rodado.

16 Según el Dr. Astuhuamán, Polía excavó en esta área en 1973 pero su informe recién se publicó en 1995. Asimismo, Astuhuamán señala que un tal Aragón también excavó en esta zona pero sus resultados aún permanecen inéditos. 


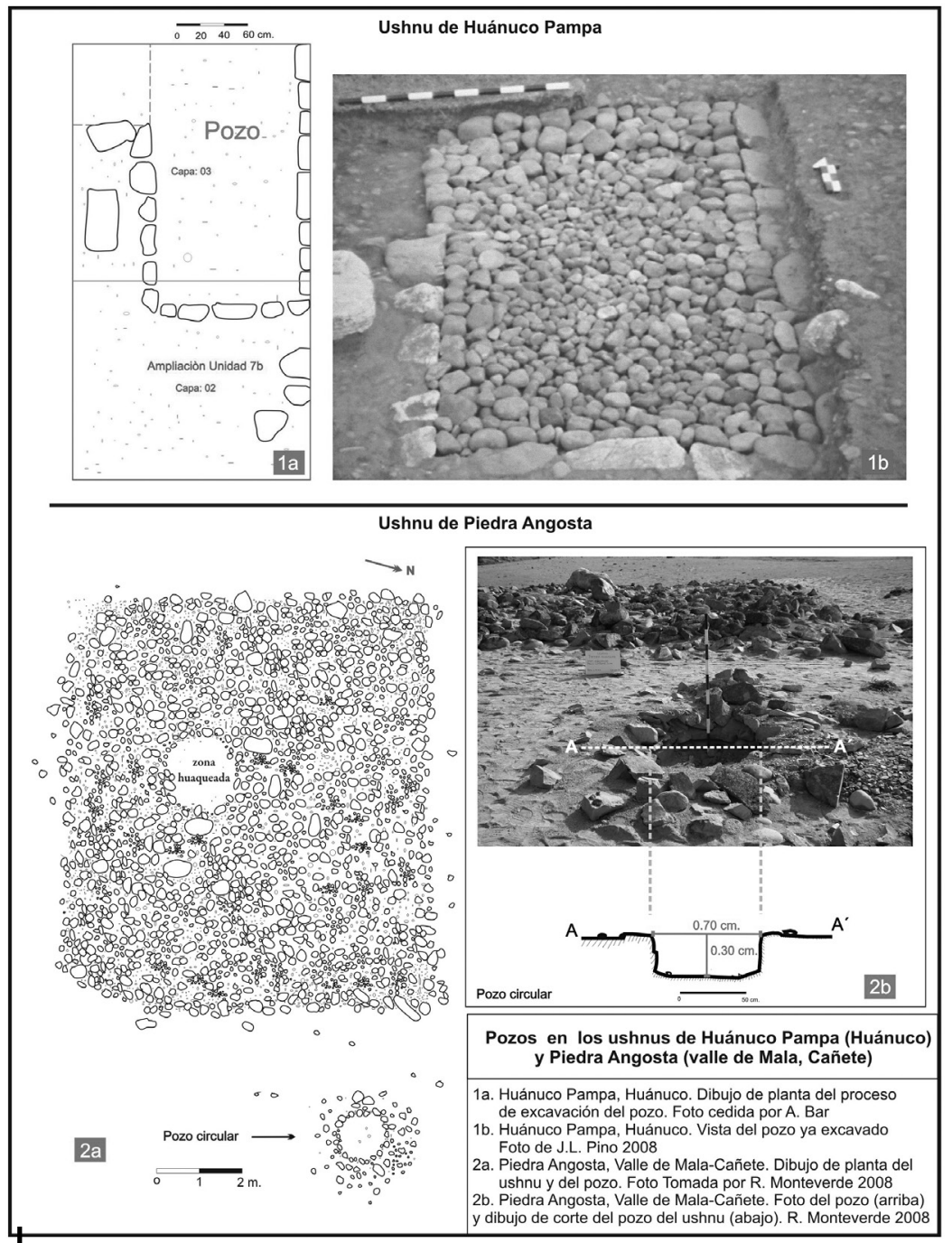

Figura 13 - A pesar de sus dimensiones diferentes, se puede ver la similitud entre el pozo de Huánuco Pampa, localizado en su plataforma superior, y la uniplataforma del ushnu de Piedra Angosta, compuesta por rocas, que presenta además un pozo circular en uno de sus extremos

Lámina diseñada por Rodolfo Monteverde S., 2010 


\section{5. Tianas (o asientos) en los ushnus}

Las tianas que se conocen (ver figs. 9-1, 4 y $6 ; 14$ y cuadro 6 ) son usualmente de piedra17. Hay una por ushnu, a excepción del de Huánuco Pampa que presenta diez asientos o tianas distribuidos en sus lados N, E y W (ver fig. 9-1) y de los cuales Pino $(2004 ; 2005)$ pudo comprobar que tenían una estrecha relación con observaciones astronómicas con el horizonte.

Asimismo, las tianas se hallan sobre la plataforma superior y han sido adosadas a una de las caras internas del muro que rodea y sobresale de la plataforma superior, lo que convierte este muro en el respaldo de la tiana (ver fig. 14-1, 2 y 5 y cuadro 6). La banqueta de la tiana puede estar cubierta de lajas y entran sentadas más de una persona. Por estar adosadas a este muro están orientas hacia la parte interna de la plataforma superior del ushnu donde se encuentra el pozo (p. ej. Huánuco Pampa, Shincal, Aypate). Es la diferencia con la tiana de Vilcashuamán que está orientada hacia la plaza. Además, es un asiento con respaldo para dos personas, tallada en un bloque de roca (González et al., 1996) y localizado inmediatamente después de la parte superior de la escalinata (ver fig. 14-3).

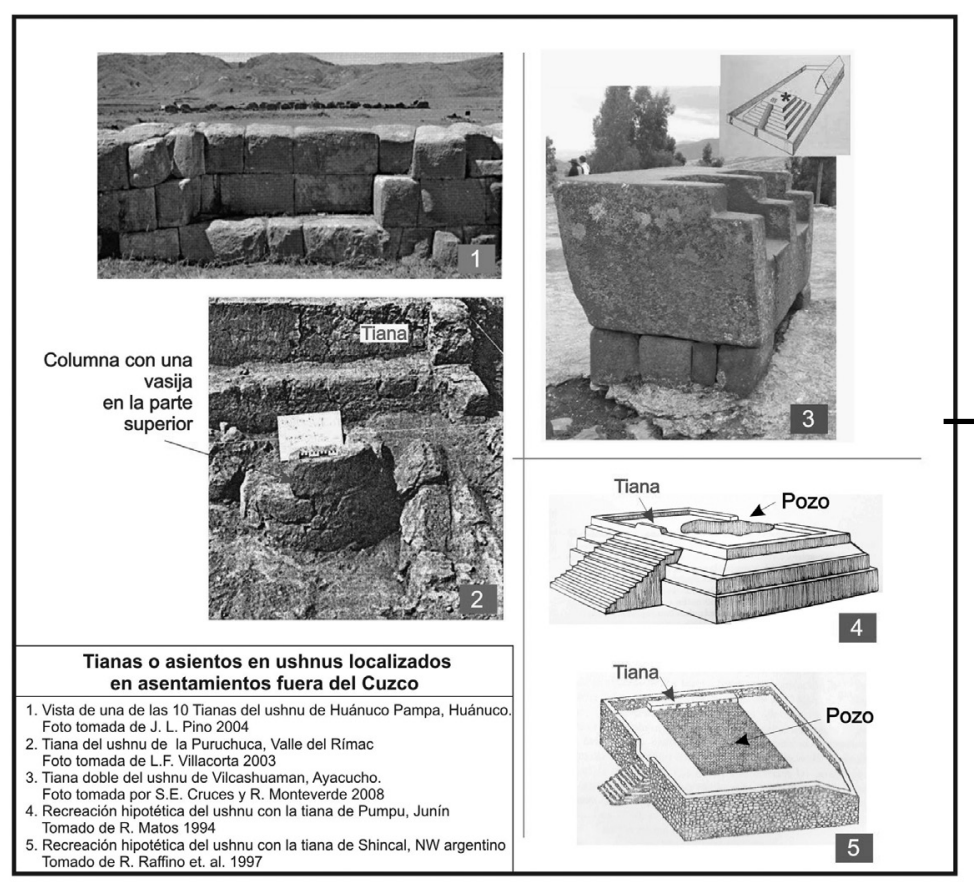

Figura 14 - Ejemplos de tianas o asientos localizados en la plataforma superior de los ushnus

En el caso de La Puruchuca la tiana no está frente a un pozo para ofrendas líquidas sino frente a una paccha que se supone habría cumplido función simbólica similar a la de los pozos. Lámina elaborada por Rodolfo Monteverde S., 2010

17 La tiana del ushnu de la Puruchuca (valle del Rímac) es de adobe, pero igualmente se encuentra en la parte superior del ushnu (ver fig. 14-2) (Villacorta, 2003). 
Cuadro 6 - Características arquitectónicas y de localización de tianas o asientos en los ushnus, localizados en asentamientos Tahuantinsuyo fuera del Cuzco

Cuadro elaborado por Rodolfo Monteverde S. 2010

\begin{tabular}{|c|c|}
\hline $\begin{array}{l}\text { Asentamiento } \\
\text { arqueológico }\end{array}$ & Características de las tianas (asientos) en los ushnus \\
\hline $\begin{array}{c}\text { Huánuco Pampa, Huánuco } \\
\text { (Pino 2010, com. pers.) }\end{array}$ & $\begin{array}{c}\text { Son } 10 \text { tianas de piedras labradas, al estilo inca imperial, y distribuidas en } \\
\text { los cuatro lados internos del muro de la plataforma superior. Están orientadas } \\
\text { hacia el pozo. }\end{array}$ \\
\hline $\begin{array}{l}\text { Pumpu, Junín (Matos, } \\
\text { 1994) }\end{array}$ & $\begin{array}{l}\text { Localizada en la parte superior de la plataforma al término de la escalinata. } \\
\text { Mide } 3,75 \mathrm{~m} \text { de largo por } 0,80 \mathrm{~m} \text { de ancho y } 0,60 \mathrm{~m} \text { de altura. Construida con } \\
\text { piedra natural irregularmente seleccionada. Tiene sobre la cubierta lajas más } \\
\text { o menos planas. Está orientada hacia el pozo. }\end{array}$ \\
\hline $\begin{array}{l}\text { Vilcashuamán, Ayacucho } \\
\text { (Prospectado por } \\
\text { Monteverde en el 2006) }\end{array}$ & $\begin{array}{c}\text { En una gran roca se tallaron dos asientos. Esta tiana se encuentra sobre } \\
\text { un pedestal de una hilada de piedras canteadas encima de la plataforma } \\
\text { superior. Está orientada hacia la plaza. }\end{array}$ \\
\hline $\begin{array}{l}\text { Shincal de Quimivil, NW } \\
\text { argentino (Raffino et al., } \\
\text { 1997) }\end{array}$ & $\begin{array}{l}\text { Localizada en el lado norte de la plataforma superior del ushnu. Banqueta o } \\
\text { escaño de paredes de piedra rellenos de mortero y asiento de bloques planos. } \\
\text { Ha sido orientada hacia el pozo. }\end{array}$ \\
\hline
\end{tabular}

\section{SEMEJANZAS Y DIFERENCIAS ENTRE LOS USHNUS CUZQUEÑOS Y LOS LOCALIZADOS EN ASENTAMIENTOS TAHUANTINSUYO FUERA DEL CUZCO}

Luego de haber analizado las probables características formales de los ushnus cuzqueños y de los que se hallan localizados en asentamientos Tahuantinsuyo fuera de la capital imperial, se nota que existe una marcada diferencia entre ellos. Consiste básicamente en la gran roca que componía los ushnus cuzqueños (Juan de Betanzos (2010 [1551]); Pedro Cieza de León (1986 [1553]); Anónimo (1906 [Circa 1565]); Pedro Pizarro (1986 [1571]); Cristóbal de Molina (2008 [15741575]); Cristóbal de Albornoz (in Duviols, 1984 [1582]) y Bernabé Cobo (in Rowe, 1981 [1653])) y las plataformas que configuraban los ushnus foráneos al Cuzco.

Luego de haber comparado las referencias etnohistóricas que mencionan los ushnus cuzqueños, además de las evidencias arqueológicas de otros asentamientos pre Tahuantinsuyo (Choquepuquio) e incaicos (Quenqo, Quispeguanca y Ampajango) (ver figs. 3 y 4), es probable que lo mencionado por los cronistas (ver cuadro 1) no diste mucho de cómo en realidad fueron los ushnus de las plazas Haucaypata, Hurin Haucaypata u otras; es decir, grandes rocas asociados con pozos y canales. En cambio, la composición básica de los ushnus de Huánuco Pampa, Aypate, Vilcashuamán, Pumpu, Curamba, Shincal de Quimivil, Tambo Colorado, Piedra 
Angosta, Maucallacta e Incahuasi-plaza del Acllahuasi, consiste en plataformas, generalmente de planta rectangular, cuadrangular o trapezoidal, de uno o más niveles sobrepuestos y, en algunos casos, con escalinatas, rampas y vanos de acceso a la plataforma superior (ver fig. 8). Pero igualmente entre estos ushnus, foráneos al Cuzco, existen diferencias en cuanto a las técnicas constructivas empleadas, el acabado en la factura del ushnu y en los materiales empleados (ver cuadros $2 ; 3$ ).

A pesar de estas diferencias, tanto los ushnus cuzqueños, descritos en las crónicas, como los localizados en diferentes asentamientos del imperio incaico presentan dos marcadas similitudes formales:

1) Su localización en una gran plaza, que usualmente es la principal del asentamiento. En el caso del Cuzco, la plaza Haucaypata (ver fig. 1 y cuadro 1). Puede, además, existir otro ushnu pero en otra plaza mucho más pequeña. Ejemplo de ello es el ushnu de la plaza Hurin Haucaypata en el Cuzco (ver fig. 1 y cuadro 1) y los ushnus de la plaza del Acllahuasi de Incahuasi y de la cancha, igualmente del Acllahuasi, de Aypate (ver figs. 5; 6 y cuadro 2). Así, la presencia del ushnu en un gran plaza se repitió en los asentamientos que fueron establecidos por los incas en diversas partes del imperio, pero no necesariamente se eligió el espacio central de la plaza. Más bien el ushnu pudo estar localizado en uno de los bordes, tanto interno como externo, de la plaza (ver figs. 5; 6; 7 y cuadro 2).

2) Las referencias etnohistóricas mencionan de manera recurrente que los ushnus del Cuzco presentaban pozos o albercas, anexados a la gran roca, con canales que salían de ellos (ver cuadro 1). Trabajos arqueológicos (excavaciones y prospecciones) en algunos ushnus localizados fuera de la llacta cuzqueña (Matos, 1994; Raffino et al., 1997; Astuhuamán, 1998; Pino, 2004; 2005; Bar, 2006-2007) han permitido comprobar la existencia de pequeños pozos de planta rectangular y de escaza profundidad, con cantos rodados en ellos. Usualmente este pozo se halla en la plataforma superior o en la parte central de la uniplataforma. Pero también puede estar fuera de ella (como en Piedra Angosta, donde el pozo es circular y de escaza profundidad) (Monteverde, 2008). Asimismo, en el caso de Huánuco Pampa (Pino, 2008), se ha podido evidenciar canales que salen de la plataforma superior, en donde se halla el pozo (ver figs. $9 ; 13 ; 10 ; 11$ y cuadro 4 ). Pensamos que tanto el pozo como el canal en los ushnus son de relevante importancia por razones funcionales, relacionadas a la ideología y cosmología incaica, que detallaremos en la discusión. Por ello no sería sorprendente que en los años venideros se logre evidenciarlos con recurrencia en excavaciones arqueológicas a realizarse en otros ushnus del Perú y Sudamérica. 


\section{PENSAMIENTO ANDINO CONTEMPORÁNEO ASOCIADO AL USHNU Y A CEREMONIAS DE OFRENDAS LÍQUIDAS Y DE LIBACIONES ACTUALES}

El pensamiento andino actual es un continuo cultural de fuertes raíces prehispánicas que ha llegado hasta nuestros días básicamente por vía oral. Cuando excavamos en la sierra de Tacna (febrero de 2010) Justino, un comunero de Vilavilani, luego de explicarnos cómo había «aparecido» el volcán Tacora (en la región colindante de Arica-Chile), nos comentó que la historia se la contó su padre y que él ya se la había transmitido a su hijo. Las palabras o las formas de narrar un mito o un cuento pueden cambiar, pero su esencia permanece y se transmite a través de las generaciones. A continuación repasaremos, en base a trabajos etnográficos, los significados que se manejan en épocas contemporáneas sobre el ushnu y las ofrendas líquidas. Probablemente se manejaron de manera parecida durante el Tahuantinsuyo.

Una de las principales preocupaciones del poblador andino es el bienestar con su entorno natural para obtener, por ejemplo, la cantidad necesaria de lluvias para la agricultura. Pero las lluvias siempre vienen con los rayos y los rayos son peligrosos porque matan el ganado e incluso, a veces, a los mismos lugareños.

«... Cuando a una persona le cae un rayo no hay que mirarla, no hay que voltear a ayudarla, porque si no muere despedazada... En vez de eso hay que seguir de frente... que tiempo después esa persona tocada por el rayo llegará a su casa sana y salva».

Así nos contó (en diciembre de 2006) una pobladora de La Unión-Huánuco, que trabajaba con nosotros durante las excavaciones del ushnu de Huánuco Pampa:

«El consejo me lo dio mi mamá que... cuando niña pastando en la pampa con mi abuela, a ésta le cayó un rayo. Mi mamá sin voltear se fue corriendo a casa y tiempo después llegó mi abuela como si nada hubiera pasado...».

En Vilavilani-Tacna y en los poblados aledaños a Quenqo Grande y Laqo en Cuzco (relatos recogidos en febrero de 2010) o en Amantaní-Puno se mantiene la idea que aquellas personas a las cuales les cayó cerca un rayo y sobreviven quedan marcadas y se convierten en sabios capaces de ver el futuro, leer las hojas de coca, determinar si habrá buenas cosechas, buenas lluvias, alimentar a la Tierra, etc. Todos creen en esas habilidades, desde el que adquiere el poder hasta los que le consultan. Por ejemplo, en Amantaní don José Quispe, el paqo o maestro del cerro Pachamama, fue elegido por el rayo:

«... por ello tiene una marca en forma de cruz en el dedo pulgar derecho...

y cada 20 de enero [fiesta del pago a la tierra] le da de comer a la tierra...» (Tuesta, 2010: 27).

Según Molina (2008 [1574-1575]) durante la fiesta de la Situa del Cuzco se llevaban al ushnu de la plaza Haucaypata, las imágenes de Viracocha Pachayachachic, el Sol, Huanacaure y Chuquilla (deidad del rayo), donde se vertían líquidos y se brindaba con ellos (Monteverde, 2010). En algunos ushnus 
localizados fuera del Cuzco, en el pozo que se localiza en su plataforma superior (p. ej. Huánuco Pampa, Pumpu o Shincal de Quimivil) o en medio de su única plataforma o estructura arquitectónica (p. ej. el ushnu de la plaza del Acllahuasi de Incahuasi y la cancha del Acllahuasi de Aypate) (ver figs. 13; 10; 11 y cuadro 4), se colocaron gran cantidad de cantos rodados que han sido colocados en épocas del Tahuantinsuyo18. Incluso en el oráculo de Catequil (otro de los nombres de la deidad del rayo) ${ }^{19}$ en Namanchugo-La Libertad, que data de épocas anteriores al Tahuantinsuyo, se hallaron gran cantidad de cantos rodados que cubrían el suelo en torno a una estructura rectangular que presenta canales y contenedores llenos de cantos rodados (Topic et al., 1999) de manera similar a muchos ushnus del Tahuantinsuyo (ver fig. 15).

Según Topic et al. (1999) en Huamachuco-La Libertad los campesinos de la zona creen que donde cayó un rayo, debe encontrarse una piedra de canto rodado. Por su parte un poblador de Laraos, Yauyos-Lima (Jiménez Borja, 1973) comenta que:

«... cuando en épocas de lluvias no llueve... va hasta la laguna de Circo, presenta hojas de coca, aguardiente y arroja piedras pequeñas lo más lejos que puede para despertar al agua dormida, ... luego llena un cántaro de agua de la orilla y sin voltear regresa a su pueblo... tras él viene la lluvia...»

De estas referencias etnográficas notamos una estrecha relación entre rayos, lluvias y cantos rodados en el pensamiento andino actual. Si llueve hay rayos, si hay lluvia hay agua en los ríos, si el caudal del agua de los ríos aumenta se «originaran» cantos rodados (piedras que adquieren una forma ovalada debido a que están siendo continuamente removidas por la fuerza del curso del agua del río que al chocar entre ellas producen un ruido o sea un «canto rodado»). Entonces, si hay cantos rodados es porque el agua de los ríos las ha originado, si hay buen caudal de agua en los ríos es porque ha llovido y si ha llovido es porque han habido rayos. Notamos entonces una cosmología andina cíclica que intenta dar una explicación del entorno natural. Así cuando un poblador comenta que donde cayó un rayo hay cantos rodados no hace otra cosa que sintetizar el proceso cíclico de las lluviasrayos-ríos-cantos rodados. Asimismo, cuando un poblador arroja piedras (cantos rodados) a las lagunas o ríos intenta reproducir simbólicamente este proceso. En relación al ushnu, Polía Meconi (citado por Astuhuamán, 1998), pudo comprobar que en épocas contemporáneas:

«... las Mushcas/muchca o piedras calientes, se emplean en los ritos para las lluvias... y que es probable que se traten de ofrendas dejadas (en el ushnu de Aypate-sierra de Piura) por los curanderos actuales...».

Luego de la conquista española, muchas deidades del panteón andino fueron asociadas con santos o vírgenes de la religión cristiana. Es así que la religión andina se cristianizó pero al mismo tiempo la religión cristiana se andinizó. Un ejemplo de

${ }^{18}$ En el relleno de algunos ushnus localizados en las alturas de Ayacucho se han encontrado gran cantidad de cantos rodados en el interior de las plataformas. Meddens y McEwan (2010, com. pers.)

${ }^{19}$ El dios del trueno, rayo y relámpago fue conocido, en diferentes regiones y en diferentes periodos en el mundo andino prehispánico, con los nombres de Illapa, Lipiaq, Pusikaqcha, Chuki Illa, Catequil, etc. (Yaranga Valderrama, 1979: 697 y 699). 


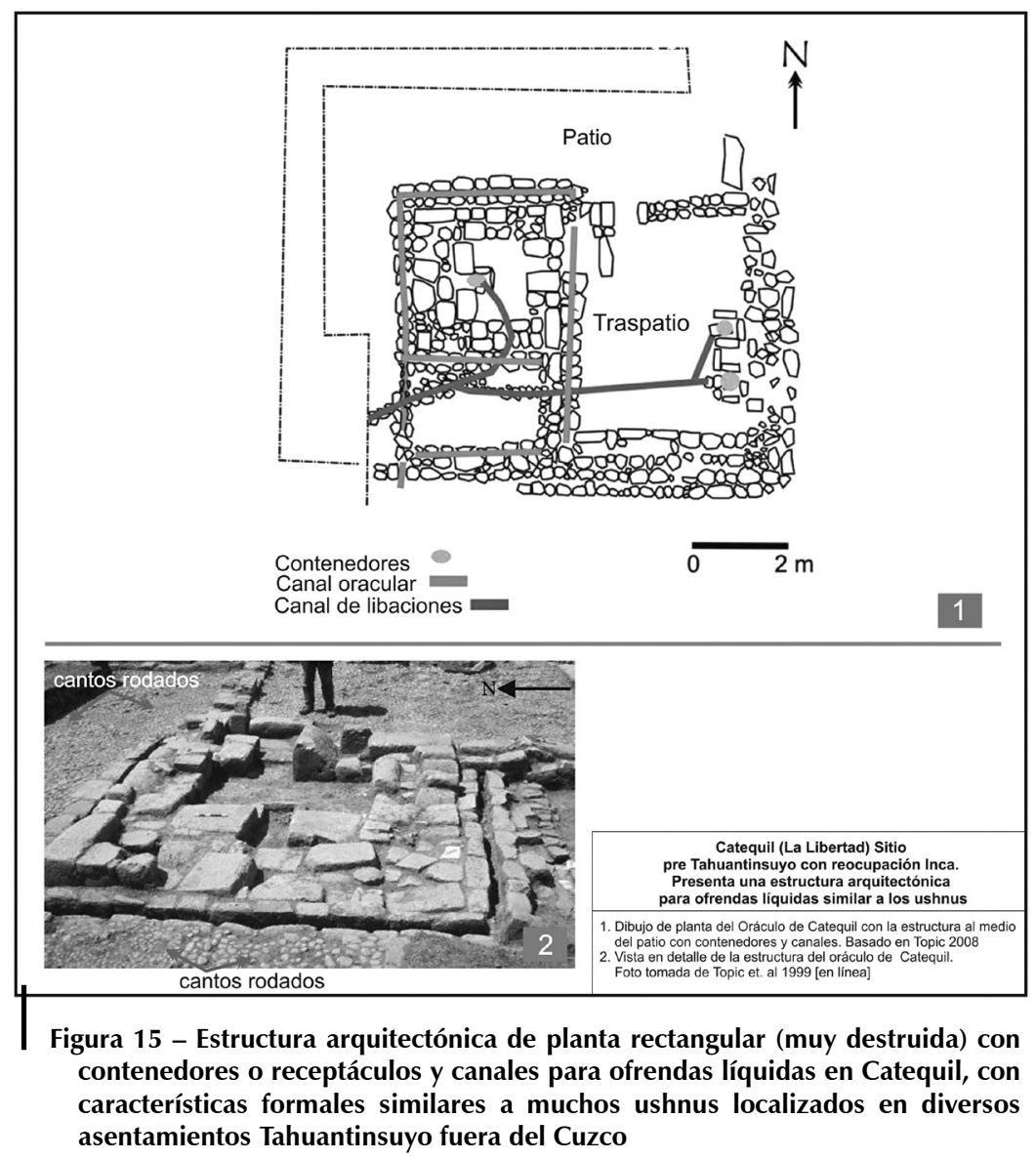

Lámina elaborada por Rodolfo Monteverde S., 2010

ello fue Illapa o dios del rayo que fue asociado con el apóstol Santiago. En épocas contemporáneas aún persiste en el pensamiento andino dicha asociación. Así lo demuestra Yaranga Valderrama (1979) quien recogió una oración dirigida a Illapa o Santiago en épocas de sequías en la zona de Víctor Fajardo y Cangallo en Ayacucho:

«... Pachanchik hina/como nuestra pacha, tiarikuq/existente, hananpi/en el mundo de arriba, uranpi/en el mundo de abajo, kaypi/en este mundo, kimsapi uklla/en tres uno, apusuyo/del chaman, churarikuq/su creador, usnu rantituk/procreador del usnu, qaqya hinaq/donador de la justicia, yaku churarikuq/creador de las aguas...».

Esta oración resalta la asociación entre el ushnu, Illapa como creador de las aguas y la visión cosmológica de la unión de los tres planos del mundo andino. En relación a este último punto, actualmente el ushnu representa, en diversas zonas del Perú, el lugar donde el agua es chupada por la tierra (zona de Tarma: Adelaar, 1977, citado por Matos, 1994). Es un hueco, subsuelo, lugar donde se filtra el agua, es 
un pozo, lugar donde hay mucho cascajo (zonas de Tarma y Ancash: Pino, 2005) o es un vaso para beber agua (zona de San Sebastián-Cuzco: información recogida por el autor en febrero de 2010).

Finalmente, hay que señalar que el concepto actual del ushnu también está asociado a enfermedades. Por ejemplo, una pobladora de la provincia de Cangallo-Ayacucho, nos comentaba (agosto 2010) que cuando a una persona se le endurece el rostro o sea cuando le da un mal aire, se llama usno-aire. Asimismo, el derramar líquidos sobre las piedras también está asociado a la buena salud de los pobladores. En Atuncolla-Puno existe una piedra cuya textura es semejante a los granos de un choclo, a la que llaman con el nombre de misa rumi o piedra milagrosa (ver fig. 16). Según los pobladores, sus poderes vienen de tiempos inmemorables. Un día el sobrino de María, por jugar cerca a esta piedra, cayó enfermo con fiebres y dolores extraños. Un paqo o maestro «... que habla con los dioses le sugirió que le regale a la roca unas cuantas copas de vino...» y así su sobrino sanaría (Tuesta, 2010: 44).

Hoy en día el ushnu, al igual que la piedra de Atuncolla, es también considerado una piedra milagrosa, un «... inkap misan [arreglo para un ritual moderno]... mesa o altar...», como el de Pumpu (en Junín) según los trabajos etnográficos de Matos (1994). Solo para hacer un paralelo etnohistórico, en la Situa (Molina, 2008 [1574-1575]), donde se expulsaban los males del Cuzco, el ushnu (una gran piedra con pozo y canales) era el eje central de las ceremonias donde se vertían líquidos y se brindada.

\section{DISCUSIÓN}

En los Andes centrales podemos denotar una larga tradición prehispánica de

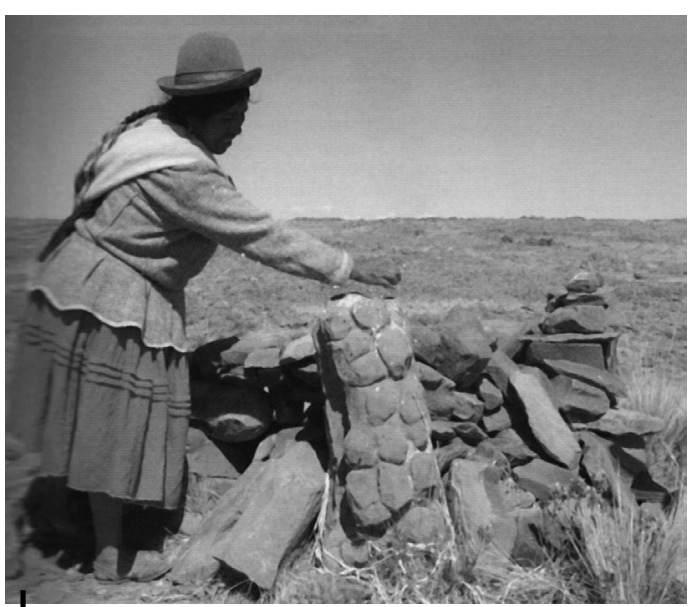

Figura 16 - María saluda la piedra milagrosa o misa rumi en Atuncolla-Puno

Fotografía tomada de Tuesta 2010: 45 rituales de libaciones. Rituales que fueron la práctica social ceremonial más importante en las que participaban los gobernantes, los difuntos y las deidades. Así por ejemplo, en relación al sector $\mathrm{A}$ de Choquepuquio (del Intermedio Tardío):

«... el agua fue esencial para la supervivencia en una sociedad agrícola [donde] los ancestros tenían la responsabilidad de mantener el aprovisionamiento y flujo de agua...» (McEwan et al., 2005: 277).

Es por ello que las estructuras A1 y A3 de Choquepuquio incluían grandes rocas con pozos y canales por donde circulaba el agua ofrendada en ceremonias de libaciones.

En el Tahuantinsuyo estas ceremonias fueron igualmente de suma importancia 
(Pino, 2010: 77). Es así que, a principios de la época de lluvias, durante la celebración de la fiesta de la Situa (Molina, 2008 [1574-1575]), 400 hombres, agrupados alrededor del ushnu de la plaza Haucaypata, partían en dirección a los cuatro suyos para arrojar los males fuera de la llacta cuzqueña20. Posteriormente, se agrupaban alrededor del ushnu de esta plaza las principales huacas del Cuzco (el Hacedor, el Sol, Huanacaure y el Trueno), el Inca, incas de privilegio y demás gentes del Tahuantinsuyo, que traían a sus propias huacas, a beber y arrojar líquidos dentro del ushnu (Monteverde, 2010).

Si comparamos las representaciones iconográficas de Guamán Poma de Ayala (2008: 193 [1615: 261]) y Martín de Murúa (2004 [1590]) en relación a las huacas, notamos que son rocas, pequeñas y medianas y de formas naturales, sin mayor alteración por tallado, y cuasi antropomorfas (ver fig. 17-1 y 2). Como se ha mencionado en el párrafo anterior Molina (2008 [1574-1575]) señala que las figuras, imágenes o estatuas del Hacedor, el Sol, Huanacaure y el Trueno se colocaban alrededor del ushnu del Haucaypata, durante la realización de la Situa, con las cuales se bebían y ofrendaban líquidos. Las formas de estas imágenes no distarían mucho de las ilustraciones de Guamán Poma y Murúa.

Al respecto, en excavaciones arqueológicas en el ushnu de Huánuco Pampa (Pino, 2010, com. pers.) se han hallado al lado del pozo de ofrendas líquidas dos pequeñas piedras erigidas sobre el suelo (ver fig. 17-3) de formas similares a las representadas por Guamán Poma y Murúa. Asimismo, en el ushnu de Incapirca Waminan (Ayacucho) (Meddens et al., 2010) se encontraron, en la base de un pozo semicircular en el parte inferior de la plataforma del ushnu, tres piedras de formas alargadas de aproximadamente unos $40 \mathrm{~cm}$ de largo (ver fig. 17-4). Además se encontró otra piedra localizada muy cerca al pozo y erigida sobre el suelo, para lo cual se talló en el costado de la roca, una suerte de borde21 que penetraba en la superficie. La pregunta es ifueron estas piedras, halladas en Huánuco Pampa e Incapirca Waminan, huacas colocadas en el ushnu durante la celebración de ceremonias de libaciones como detalla Molina en su relato de la Situa celebrada en el Cuzco? Y żacaso estas piedras están asociadas al Hacedor, al Sol, a Huanacaure o al Trueno? Responderemos a estas preguntas en una futura investigación.

Los rituales de libaciones o de arrojar líquidos sobre las piedras, a pesar de los siglos que nos separan del Tahuantinsuyo, aún persisten en la actualidad. En ceremonias o rituales andinos cuando se realizan pagos a la tierra (en pro de una buena siembra y cosecha), se rinde culto a las lluvias, los rayos, los cerros o se pide por la buena salud (ver fig. 16) como se hacía en la fiesta de la Situa (Molina, 2008 [1574-1575]). Incluso persiste en la mentalidad del poblador andino la creencia que el ushnu es el lugar donde entra, o chupa la tierra, el agua.

20 Se arrojaban los males a los ríos Quiquisana (en el Collasuyo al SE, Apurímac (en el Chinchaysuyo al NW), Pisac (en el Antisuyo al NE) y Cusibamba (en el Cuntisuyo al SW) (Molina, 2008 [1574-1575]) (ver Monteverde, 2008).

21 En otros ushnus de la zona de Ayacucho se han evidenciado igualmente piedras peculiares de formas y tamaños similares en el interior de la plataforma (Meddens y McEwan, 2010, com. pers.). 


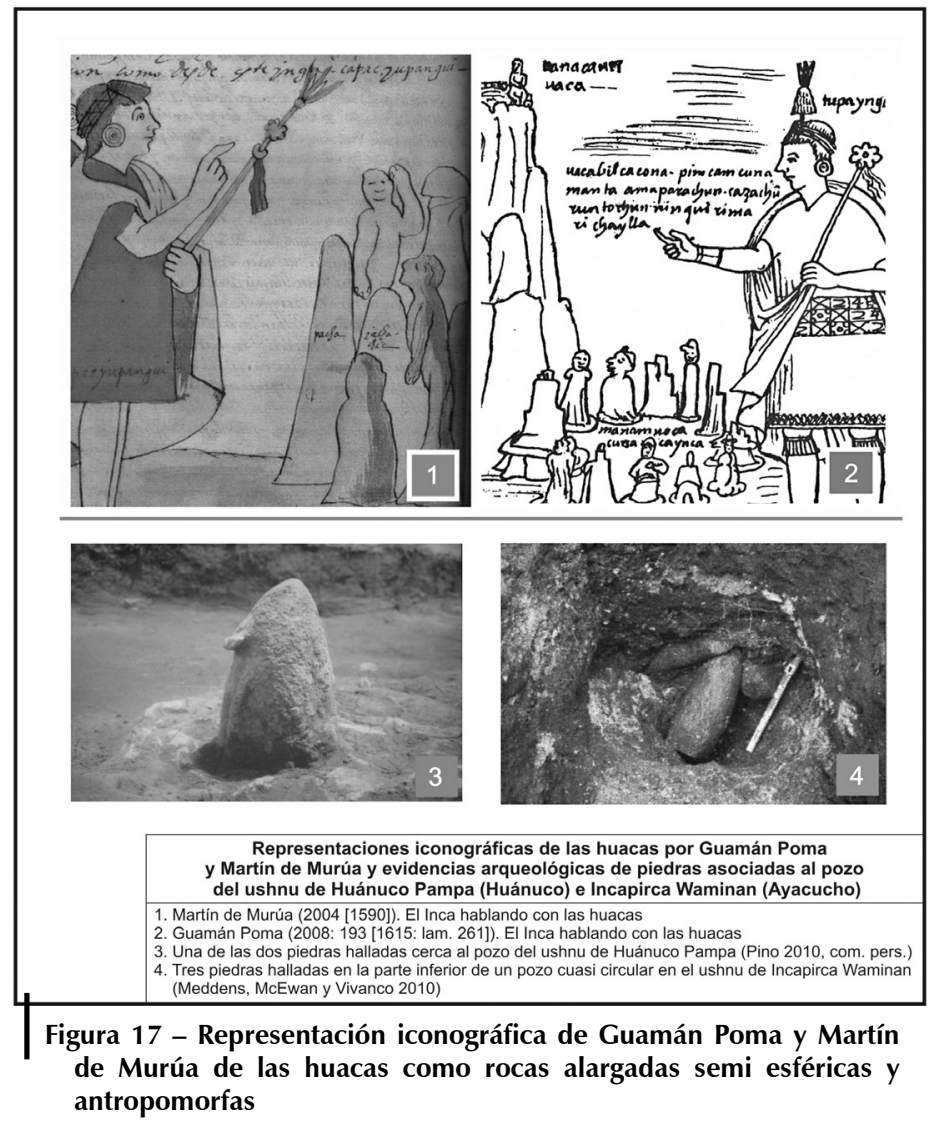

Rocas de formas similares se han hallado asociadas al pozo de los ushnus de Huánuco Pampa e Incapirca Waminan. Lámina diseñada por Rodolfo Monteverde S., 2010

En relación a las ofrendas líquidas en el Tahuantinsuyo, Pablo José de Arriaga (1920: 42 [1621: cap. IV]) señala que:

«la principal ofrenda y la mejor... es la chicha por ella, y con ella comienzan todas las fiestas de las huacas... Y assi tienen para este efecto muchos vasos, y vasijas de diferentes formas, y materias, y... que dan de beber a las huacas...».

Esta cita es importante porque Arriaga señala la existencia de toda una parafernalia que permitía realizar con éxito las ceremonias de libaciones o de ofrendas líquidas (chicha). Ahí se han identificado los Yllapa Usno (Pino, 2010) que son recipientes de libaciones de carácter mueble, que cada ancestro de cada grupo social poseía para poder brindar.

Pero ya desde épocas pretéritas a la formación estatal del Tahuantinsuyo, asociados a las rocas de Choquepuquio (McEwan et al., 2005) (ver figs. 3; 15), se han encontrado en excavaciones arqueológicas jarras, vasos, coladores y vasijas 
empleados en ceremonias de libaciones. Estos líquidos, como la chicha, eran vertidos en pozos y contenedores comunicados con canales aledaños a las rocas en Choquepuquio. Estos pozos y canales también están presentes en los ushnus cuzqueños, descritos en las crónicas españolas de Juan de Betanzos (2010 [1551]), Pedro Pizarro (1968 [1571]) y Cristóbal de Molina (2008 [1574-1575]), así como en los ushnus localizados en asentamientos Tahuantinsuyo fuera de esta llacta (p. ej. Huánuco Pampa, Pumpu, Shincal de Quimivil, Aypate, Incahuasi) (ver fig. 9).

Ya hemos mencionado que en la fiesta de la Situa del Cuzco se vertían líquidos dentro del ushnu. Asimismo, autores como Zuidema (1979; 1989) han mencionado que una de las intenciones de ello era interrelacionar simbólicamente los tres mundos de la cosmovisión andina o sea el Hanan Pacha (alto), el Cay Pacha (medio) y el Oco pacha (bajo). Pero ¿cómo se podía hacer esto visualmente posible en una ceremonia? o sea ¿cómo se podía materializar esta cosmología? Para eso, en épocas pre Tahuantinsuyo, se utilizaban vasijas ceremoniales o pacchas22, que eran recipientes con dos orificios, uno de entrada y otro de salida, para el agua que se vertía sobre la tierra (Carrión Cachot, 2005) (ver fig. 18-1). De esta manera se representaba el recorrido simbólico del agua a través de estos tres planos verticales. Dichas ceremonias y el empleo de estas pacchas perduraron en épocas del incanato e incluso persiste su uso en épocas contemporáneas con la intención de derramar líquidos sobre la Pachamama para propiciar, por ejemplo, una buena temporada de lluvias en época de siembra.

Con los ushnus, cuya idea de circulación simbólica del agua vertida en ellos no dista mucho al de las pacchas (ver fig. 18-3 y 4) e incluso al de las rocas y estructuras arquitectónicas pre Tahuantinsuyo en Choquepuquio en el Cuzco (ver fig. 18-2), una solución fue la de implementarles pozos y canales a través de los cuales entraba y circulaba el agua vertida. Debido al rol público de los ushnus, el pozo tenía que ser visible, por ello estaba localizado en la plataforma superior, en el caso de los ushnus foráneos al Cuzco, o anexados a la roca, en el caso del Cuzco, según las crónicas consultadas.

En muchos de los pozos de los ushnus (ver figs. 13; 10; 11) se han hallado cantos rodados o piedras ovaladas en su interior. Al respecto Betanzos (2010: 219 [Cap. XLII]) señala que cuando Huayna Capac salió 20 leguas23 del Cuzco:

«... entraba en el pueblo... [y en la plaza] le tenían hecho cierto asiento a manera de un castillejo alto y en do medio del castillejo una pileta llena de piedras... y subiase en aquel castillejo y allí se sentaba en su silla y de ahí veía todos en la plaza... luego vaciaban delante mucha chicha en aquella pileta que allí estaba... y él bebía con ellos...».

22 González Holguín (1989): 268 y 358 [1608]) traduce: Ppacha como fuente, chorro de agua, canal caño; Ppaccchaylla ppacchak vnu, ppacchay ppachayll Iluksik como agua o chorro que corre o agua de pie; Ppaccharcarin como agua que corre por muchos años. Y a su vez traduce Vsnu como tribunal de juez de una piedra hinchada.

23 Una legua mide aproximadamente cinco kilómetros (Hyslop, 1990: 35). 




Para ello se implementaron pozos y canales para la circulación de líquidos vertidos en los ushnus. Resalta la presencia de cantos rodados en los pozos de fuerte connotación simbólica asociada a las lluvias y los rayos. Lámina diseñada por Rodolfo Monteverde S., 2010

Pero ipor qué colocar o dejar cantos rodados en el pozo de los ushnus en épocas del Tahuantinsuyo? El análisis etnográfico que hemos realizado nos puede ayudar a entender el por qué de la implementación de pozos con cantos rodados en los ushnus durante el incanato.

En el pensamiento andino contemporáneo persiste el concepto de emplear cantos rodados en ceremonias propiciatorias de las lluvias o incluso se les arrojan a los ríos con el mismo fin. Asimismo, se cree que donde cayó un rayo debe haber cantos rodados e incluso, en épocas de sequías, le rezan a Illapa o Santiago, nombres empleados en épocas prehispánicas y desde la Colonia, respectivamente, para designar al dios del rayo. Es decir, actualmente existe una estrecha relación entre lluvias, rayos, agua de los ríos y cantos rodados. Pero las fuentes etnohistóricas, también hacen alusión a esta asociación como Molina (2008 [1574-1575]) con la fiesta de la Situa, donde alrededor del ushnu se le rendían ofrendas líquidas a 
Chuquilla, otro de los nombres del rayo. Esta deidad tenía su propio santuario, con anterioridad al Tahuantinsuyo, en la zona norte del Perú, donde era conocido como Catequil24 (Topic et al., 1999). En el patio que rodea la estructura principal de este santuario y en los contenedores asociados a canales hay gran cantidad de cantos rodados. Si volvemos a las fuentes etnohistóricas, Illapa, o Catequil o Chuquilla producía los rayos arrojando piedras con su honda (Castro de Trelles, 1992).

Los incas materializaron simbólicamente el ciclo natural de las lluvias que recorren verticalmente el Hanan (arriba), el Cay (al medio) y Oco pacha (abajo) a través de la construcción de pozos con cantos rodados en su interior y canales en los ushnus. Los pozos se volvieron el eje central de los ushnus, al colocárselos al centro de la plataforma superior. Al mismo tiempo el ushnu pasó a ser el eje central de los asentamientos construidos durante la expansión imperial, con las ceremonias de libaciones que se practicaban en sus plazas principales.

Entre las estrategias empleadas por el Tahuantinsuyo, en los diversos territorios por donde se expandió, el empleo de mano de obra local o de tradiciones constructivas fue importante, tal vez, como parte de una interrelación social y política, donde el imperio se hacía presente, por ejemplo, con la intención de erigir un ushnu. Pero los pueblos locales también se hacían presentes con el uso de técnicas o tradiciones propias para la construcción del ushnu. Así lo deja entrever Villacorta (2003), en relación a los ushnus del valle del Rímac, al proponer que estos pudieron haber representado una rápida y eficiente capacidad de reacción (adecuación) de los curacas locales ante el nuevo orden establecido por los incas; y, viceversa, en la reutilización por parte de los incas de estos espacios ya ocupados antes de su llegada a la costa.

En la expansión territorial incaica los centros administrativos fueron de suma importancia ya que les permitieron controlar las fuerzas productivas, a través del reconocimiento de las potencialidades tanto horizontales como verticales de los pisos ecológicos (Murra, 2007), con lo cual pudieron sustentar el aparato político y militar del imperio y de los grupos étnicos que controlaban. Recordemos que en muchos centros administrativos (p. ej. Vilcashuamán y Pumpu) y centros provinciales (p. ej. Huánuco Pampa) existen ushnus en sus plazas principales (Ver fig. 7). Estas, a pesar de las diferencias en su tamaño o trazado, cumplieron un rol resaltante en los planes estratégicos de alianzas entre el incanato y los territorios donde se asentaban. Al respecto ya hemos visto el rol de la plaza Haucaypata del Cuzco durante la Situa como espacio integrador, pero a la vez diferenciador de los grupos sociales.

Otro ejemplo sería la plaza de Vilcashuamán donde se reforzaba la subordinación de una serie de grupos sociales locales hacia el Cuzco (González Carré \& Pozzi-

${ }^{24}$ La fama de Catequil se extendió más allá de los límites de Huamachuco, desde Quito hasta Cuzco. Su huaca fue llevada al Cuzco cuando se produjo la conquista incaica como símbolo de dominación sobre los Huamachucos (Castro de Trelles, 1992: LIX), pero también como de negociaciones. Recordemos que la religión inca más que excluyente fue incluyente, donde el culto a deidades ajenas al panteón incaico tuvo un fuerte trasfondo de relaciones simétricas y asimétricas con los pueblos anexados al imperio. 
Escot, 2002). En la plaza de Huánuco Pampa, Shea (1966) y Morris \& Covey (2003), evidenciaron como resultado de sus excavaciones en el ushnu y en algunas estructuras aledañas a la plaza, gran cantidad de restos de comida y vasijas empleadas en ceremonias de libaciones. Así, la plaza de Huánuco Pampa, localizado en una extensa y desolada pampa, o de otro asentamiento inca, fue el escenario de diversas ceremonias en las cuales participaban tanto grupos locales como grupos representantes del Tahuantinsuyo, con la intención de reforzar las relaciones sociopolíticas entre ambos.

El camino inca que cruza estos asentamientos, en algunos casos muy cerca al ushnu, refuerza la intención de materializar la importancia de la plaza y el ushnu, al ser ambos una suerte de nudo dentro de una gran vía de comunicación a través del incanato.

Si comparamos los diferentes planos de los asentamientos Tahuantinsuyo de Sudamérica (ver figs. $5 ; 6$; 7) vamos a reparar que no existió un plano base que se haya repetido de manera ortodoxa con la intención de imitar al de la capital cuzqueña (Farrington, 1998), ya que se tomaron en cuenta aspectos como: características naturales, estrategias políticas, económicas locales, etc. (Bonavía, 1972; Gasparini \& Margolies, 1977; Canziani, 2006). Pero lo que sí es evidente es la recurrencia de cierta infraestructura «tipo» como las plazas, que organizaban la distribución espacial de los asentamientos, las canchas, el templo del Sol, la kallanca, el ushnu, entre otros, que reflejarían la materialización del concepto ideal de Cuzco como llacta que los incas tenían (Farrington, 1998).

Por ello apoyamos el enunciado de Gasparini \& Margolies (1977) quienes proponen que la idea fue repetir los modelos funcionales, rituales y simbólicos del sistema estatal incaico a partir del modelo cuzqueño, donde se tomaron el significado y las funciones de las formas antes que las formas mismas de los edificios, plazas y canchas. Por ello esta infraestructura «tipo» presenta una serie de variaciones a pesar de cumplir una función específica. Pensamos que los ushnus son un buen ejemplo de ello.

Es así que se encuentra una serie de variaciones en el diseño y emplazamiento de los ushnus dentro de los asentamientos Tahuantinsuyo fuera del Cuzco. Pero se nota que se mantuvieron ciertos conceptos bases que se repiten como, por ejemplo, su ubicación al centro o al borde de una gran plaza, estar compuesto por una o varias plataformas superpuestas, ser de planta rectangular, cuadrangular y trapezoidal, contar con una gran escalinata y/o rampa, tener tianas (asientos), pozos y canales. Lo que llama la atención es que en el Cuzco aún no se ha podido evidenciar si los ushnus de las plazas principales de la capital incaica fueron grandes plataformas superpuestas. Nos inclinamos a pensar que no, que más bien el concepto habría girado en torno al de una gran roca localizada en medio de las plazas como en la actualidad se ha evidenciado en Choquepuquio (Intermedio Tardío) y en Quenqo Grande, Quispeguanca y Ampajango 2 (sitios Tahuantinsuyo) (ver fig. 4).

Pero el significado simbólico y funcional de los ushnus cuzqueños habrían prevalecido en los ushnus localizados fuera de ella, es decir el de ser el lugar donde se ofrendaban líquidos, ser el eje de las actividades ceremoniales como 
la fiesta de la Situa. Hay que recordar además, que dicha fiesta se realizaba en diferentes partes del Tahuantinsuyo y que el asentamiento donde el Inca se encontrara se volvía el centro y la capital del Tahuantinsuyo (Ziólkowski, 1996). Por ende el rol del ushnu era de suma importancia porque materializaba dicha centralidad en diversos asentamientos. Entonces, la presencia del ushnu dentro de la plaza principal de un asentamiento denota el rol público que tenía, al igual que las actividades estatales realizadas por el Inca (Ziólskowski, 2002) quien era el único capaz de conversar con las huacas (además de ciertas personas especiales designadas por el mismo Inca como el willaq umu), destruirlas o favorecerlas con tierras o regalos (como en la Situa) o encabezar ceremonias propiciatorias de buenas épocas para la agricultura, al enfrentarse a las fuerzas naturales desde el ushnu (Zuidema, 1979; 1989; Ziólskowski, 2002).

Por ello los incas implementaron los ushnus localizados fuera del Tahuantinsuyo con escalinatas que se iniciaban desde la misma plaza y que permitían el ascenso y descenso a la parte alta de la plataforma superior. De esta forma las escalinatas se convierten en una suerte de nexo entre el ushnu y la plaza, donde todos podían ver quien subía o bajaba. En muchos ushnus, en la plataforma superior existe un espacio amplio donde además hay tianas o asientos. Estos no fueron diseñados para una sola persona, sino para dos. Por otro lado, la intención de orientar las tianas hacia la parte interna tendría que ver con el manejo espacial de la plataforma superior donde se realizaban las actividades ceremoniales de libaciones en el pozo. Caso contrario sería la tiana del ushnu de Vilcashuamán que está orientada hacia la plaza principal, en donde había según Cieza de León (1962: 237 [1533: LXXXIX]):

«... otra piedra no pequeña... a manera de pila, donde sacrificaban y mataban los animales y niños tiernos....».

Eso significa que, al adosar las tianas a los muros, se dejaba mayor espacio libre para, entre otras intenciones, construir el pozo, contar con un espacio libre en la parte central de la plataforma superior y tener la mayor visibilidad de los cuatro lados internos del ushnu y externos o sea de la plaza. Caso peculiar es la tiana del ushnu de La Puruchuca (valle del Rímac) (Villacorta, 2003) que no está frente a un pozo sino frente a una columna de planta circular de escasa altura sobre la cual se ha colocado una vasija con un orificio en su base (ver fig. 14-2). Se puede suponer, que se trataría de una paccha (vasija ritual empleada en ceremonias de libaciones).

Como vemos, existe una clara intención de relacionar espacialmente las tianas, escalinatas y pozos. Eso significa que ninguna de estas está disociada de las demás, por ende las funciones que cumplían, por ejemplo, durante las ofrendas líquidas, eran simultáneas: ascenso al ushnu, lugar de ocupación de los personajes principales y realización y visualización pública, desde la plaza principal, de las actividades ceremoniales realizadas en la plataforma superior del ushnu.

Finalmente deseamos comentar que los pronósticos y vaticinios realizados en el ushnu, por ejemplo, sobre el éxito de la siembra y otros asuntos estatales del Tahuantinsuyo, libando y vertiendo líquidos en los pozos de los ushnus, como 
señalan las crónicas, no fueron dejadas al azar o fueron un engaño por parte del incanato. Se piensa que fueron la materialización o la manifestación visual y ceremonial del resultado analítico y consiente de un grupo de personas entendidas en política, economía, estrategias militares, etc. y que era justificado a través de la ceremonialidad o visualización del poder del Inca durante las ceremonias de libaciones para propiciar una época de siembra, de lluvias, de buena salud, etc. Era el sitio donde la relación con el entorno natural se construye, se entiende de determinada manera y se acepta como parte del pensamiento de sus pobladores, mas no se impone.

\section{CONCLUSIONES}

Debido a la ausencia de evidencia arqueológica en relación a los ushnus del Cuzco, hemos basado nuestro análisis en las fuentes etnohistóricas. Estas, al haberlas confrontado, empleando principalmente las del siglo XVI, coinciden básicamente en describirlos como rocas con pozos y canales donde de libaban y vertían líquidos en determinadas fiestas político religiosas como la Situa. El autor opina que las rocas de Quenqo Grande (Parque de Sacsayhuaman) y Quispeguanca (Valle del Urubamba), ambas localizadas en el Cuzco y de filiación incaica, e incluso Choquepuquio (Cuzco) del Intermedio Tardío, pueden ser empleadas para confrontar los datos etnohistóricos y entender, en base a evidencia material indirecta, cómo eran los ushnus del Cuzco que, a nuestro entender, no serían muy diferentes de lo que se menciona en las fuentes etnohistóricas. Pero solo una excavación sistemática en, por ejemplo, la plaza de Armas del Cuzco, podrá reforzar o refutar esta propuesta.

Los ushnus localizados fuera del Cuzco, a lo largo de los territorios por donde se expandieron los incas, se caracterizan básicamente por ser de planta cuadrangular o rectangular, presentar una o más plataformas superpuestas, tener una escalinata de acceso, presentar tianas o asientos y estar localizados en la plaza principal del asentamiento. Pueden estar localizados desde la parte central, un borde interno o externo de la plaza. Estas características mencionadas son variadas, como el volumen y las técnicas constructivas de los ushnus. Así por ejemplo, si el ushnu era pequeño no era necesario una escalinata de acceso o no presentaba tianas o asientos en su parte superior. Pero en todo caso se encuentra una relación intencional entre la localización del ushnu en un espacio público (plaza) como la orientación de la escalinata hacia la parte interna de la misma. El autor cree, como se ha evidenciado en excavaciones arqueológicas en algunos ushnus, que es de suma importancia la presencia de un pozo lleno de cantos rodados y canales. Opina también que otras excavaciones en otros ushnus pueden evidenciar los mismos resultados. Por ello se propone que los pozos y canales son de suma importancia para considerar estas estructuras como ushnus.

Existe una gran diferencia morfológica entre los ushnus mencionados por los cronistas sobre los ushnus del Cuzco, los cuales habrían sido grandes rocas localizadas en medio de las plazas y los evidenciados fuera de esta llacta, que 
como se comenta, son grandes o pequeñas plataformas de planta cuadrangular o rectangular. Están igualmente localizados en una plaza, la principal, del asentamiento. Lo que sí es recurrente entre ambos, es la presencia de pozos y canales donde se libaban y vertían líquidos. Pensamos que lo más importante no fue una representación ortodoxa o de imitación formal de los edificios o estructuras arquitectónicas de la llacta cuzqueña, como los ushnus, sino más bien su representación y recreación funcional, como la de ser contenedores donde se libaban y vertían líquidos en pozos construidos en su interior. Por ello el autor opina que ésta fue una de las funciones principales, tal vez la más importante, que cumplieron los ushnus a nivel territorial del Tahuantinsuyo.

En base a trabajos etnográficos se puede decir que en el pensamiento andino actual persiste el concepto del ushnu como lugar donde se ofrendan líquidos, o lugar donde ingresan, etc. Asimismo, los cantos rodados encontrados en los ushnus están asociados, en la actualidad, con las lluvias, los ríos, los rayos, con Illapa o Santiago; e incluso se vierten líquidos (vino por ejemplo), para tener buena salud, sobre algunas rocas, como así se hacía en épocas del Tahuantinsuyo, según las crónicas de la Colonia. Por ende no se descarta que similar significado haya tenido en el Tahuantinsuyo. Al entender las prácticas rituales actuales se puede tener una idea o generar hipótesis sobre la funcionalidad de los ushnus, es decir se trata de proponer practicar una arqueología que parta desde el propio territorio y que no importe propuestas teóricas o ideológicas foráneas que serían muy alejadas de nuestra realidad arqueológica. Algunos podrán alegar que no hay un solo pensamiento andino, con lo cual estamos de acuerdo, pero pensamos que es más conveniente tratar de encontrar las similitudes entre los pensamientos andinos contemporáneos, no solo superficialmente, sino en su trasfondo social ideológico.

\section{Agradecimientos}

A mi familia, a Ernestito y a las personas (profesores, colegas y amigos) que me ayudaron en la elaboración de este artículo.

\section{Referencias citadas}

AGURTO CALVO, S., 1987 - Estudios acerca de la construcción, arquitectura y planeamiento incas, 295 pp.; Lima: Cámara Peruana de Construcción.

AMORÍN GARIBAY, J. \& ALARCÓN GUTIÉRREZ, E., 2001 - Exploración arqueológica en Curamba y su relación con Sondor. In: Actas del XII Congreso Peruano del Hombre y la Cultura Andina «Luis Guillermo Lumbreras», Tomo II (I. Pérez, W. Aguilar \& M. Purizaga, eds.): 287-293; Lima.

ANGLES VÁRGAS, V., 1990 - Sacsayhuaman, portento arquitectónico, 184 pp.; Cusco: Industrial Gráfica.

ANÓNIMO, 1906 [Ca. 1565] - Discurso de la sucesión y gobierno de los yngas. In: Juicio de límites entre el Perú y Bolivia; prueba peruana presentada al gobierno de la República Argentina, Vol. 8 (V. M. Maúrtua, editor): 149-165; Madrid: Tipografía de los Hijos de M. G. Hernández. 
Tahuantinsuyo: la arquitectura de los ushnus como espacios de libaciones y ofrendas líquidas

ARRIAGA, P. J. de, 1920 [1621] - La extirpación de la idolatría en el Perú. Tomo I, segunda serie; Lima: Imprenta y Librería Sanmartín y Ca. Colección de libros y documentos referentes a la historia del Perú. Anotaciones y concordancias con las crónicas de Indias por Horacio Urteaga.

ASTUHUAMÁN, C., 1998 - Asentamientos incas en la sierra de Piura; Lima: Universidad Nacional Mayor de San Marcos, Facultad de Ciencias Social, Escuela de Arqueología. Tesis de Licenciatura.

ASTUHUAMÁN, C., 2008 - El ushnu inca visto desde la arqueología. Ponencia dada en el marco de la conferencia «El ushnu inca, arqueología, paisaje y poder»; Lima: Centro Cultural Británico de Miraflores.

BAUER, B., 2000 - El espacio sagrado de los incas. El sistema de ceques del Cuzco, 239 pp.; Cuzco: Centro de Estudios Regionales Bartolomé de las Casas. Archivos de Historia Andina 33.

BAUER, B., 2008 - Cuzco antiguo. Tierra natal de los incas, 452 pp.; Cuzco: Centro de Estudios Regionales Andinos Bartolomé de las Casas. Archivos de Historia Andina 43.

BETANZOS, J. de, 2010 [1551] - Suma y narración de los incas, 342 pp.; Lima: Fondo Editorial de la Unidad de Posgrado de la Facultad de Ciencias Sociales de la Universidad Nacional Mayor de San Marcos. Edición, introducción y notas de María del Carmen Rubio.

BONAVÍA, D., 1972 - Factores ecológicos que han intervenido en la transformación urbana a través de los últimos siglos de la época precolombina. In: Actas y memoria del XXXIX Congreso Internacional de Americanistas «El proceso de urbanización en América desde sus orígenes hasta nuestros días» Vol. 2: 79-97; Lima: Instituto de Estudios Peruanos.

CANZIANI AMICO, J., 2006 - El imperio inka. La integración macrorregional andina y el apogeo de la planificación territorial, 104 pp.; Lima: Cuadernos Arquitectura y Ciudad. Departamento de Arquitectura de la Pontificia Universidad Católica del Perú (PUCP), n. ${ }^{\circ} 2$.

CARRIÓN CACHOT, R., 2005 - El culto al agua en el antiguo Perú, 209 pp.; Lima: Instituto Nacional de Cultura.

CASTRO DE TRELLES, L. (ed.), 1992 - Relación de la Religión y ritos del Perú hecha por los padres agustinos, Ixxxviii +74 pp.; Lima: Pontificia Universidad Católica del Perú, Fondo Editorial. Estudio preliminar y notas de L. Castro de Trelles.

CAVERO, Y., 2009 - Ushnus y santuarios en las punas de Huancasancos y Lucanas, Ayacucho. Kullpi. Investigaciones culturales en la provincia de Huaral y el norte chico, Año 4, n. ${ }^{\circ}$ 4: 295-293; Lima.

CIEZA DE LEÓN, Pedro, 1962 [1553] - La Crónica del Perú, 294 pp.;Madrid: Espasa Calpe. Colección Austral DVII

CIEZA DE LEÓN, Pedro, 1986 [1553] - Crónica del Perú. Segunda Parte, 238 pp.; Lima: Academia Nacional de la Historia, Pontificia Universidad Católica del Perú.

D`ALTROY, T., 2003 - The incas, 408 pp.; Malden: Blackwell. Inglaterra.

DEMARRAIS, E., CASTILLO, L. J. \& EARLE, T., 1996 - Ideology, materialization and power strategies. Current Anthropology. Vol. 37, n. ${ }^{\circ}$ 1: 15- 31.

DICCIONARIO DE LA LENGUA ESPAÑOLA, 2001 - Real Academia de la Lengua Española. 10 tomos; España: Mateu Cromo. Artes Gráficas, S.A.

DUVIOLS, P., 1984 - Albornoz y el espacio ritual andino prehispánico. Instrucción para descubrir todas las guacas del Piru y sus camayos y haziendas [1582]. Revista Andina, Año 2, n. ${ }^{\circ}$ 1: 169-222; Cuzco: Centro de Estudios Regionales Andinos Bartolomé de las Casas. 
FARRINGTON, I., 1995 - The mummy, palace and estate of inka Huayna Capac at Quispeguanca. Tahuantinsuyu, una revista internacional de estudios inkas, Vol. 1: 55-65; Australia: Brola Press Pty Ltd.

FARRINGTON, I. \& RAFFINO, R., 1996 - Mosoq suyukunapa tariqnin; nuevos hallazgos en el Tahuantinsuyo; inka news fron around the empire. Tahuantinsuyu, una revista internacional de estudios inkas, Vol. 2: 73-77; Australia: Brola Press Pty Ltd.

FARRINGTON, I., 1998 - The concept of Cuzco. Tahuantinsuyu, una revista internacional de estudios inkas, Vol. 5: 53-59; Australia: Brola Press Pty Ltd.

GARCILASO DE LA VEGA, El Inca, 2005 [1609 ] - Comentarios reales de los incas, 2 vols., 411 pp. + 465 pp.; México DF.: Fondo de Cultura Económico. Edición, índice analítico y glosario: Carlos Aranibar.

GASPARINI, G. \& MARGOLIES, L., 1977 - Arquitectura inka, 357 pp.; Caracas: Universidad Central de Venezuela. Centro de Investigaciones Históricas y Estéticas.

GONZÁLEZ CARRÉ, E. \& POZZI-ESCOT, D., 2002 - Arqueología e etnohistoria en Vilcashuamán. Boletín de Arqueología PUCP, n. ${ }^{\circ}$ 6: 79-105; Lima.

GONZÁLEZ CARRÉ, E., COSMÓPOLIS, J. \& LÉVANO, J., 1996 - La ciudad inca de Vilcashuamán, 118 pp.; Ayacucho: Universidad Nacional de San Cristóbal de Huamanga.

GONZÁLEZ HOLGUÍN, D., 1989 [1608] - Vocabulario de la lengua general de todo el Perú Ilamada lengua qquichua o del Inca, xliv+697 pp.; Lima: Editorial de la Universidad Nacional Mayor de San Marcos (UNMSM). Ramiro Matos Mendieta (presentación) y Raúl Porras Barrenechea (prólogo).

GUAMÁN POMA DE AYALA, F., 2008 [1615] - Nueva corónica y buen gobierno, 3 vols.; México DF.: Fondo de Cultura Económico. Franklin Pease G.Y. (edición y prólogo), Jan Szeminski (vocabulario y traducciones).

HOLLAND, A., 2008 - Nueva corónica: tradiciones artísticas europeas en el Virreinato del Perú, 229 pp.; Cuzco: Centro de Estudios Regionales Andinos Bartolomé de las Casas.

HYSLOP, J., 1985 - Inkahuasi, el nuevo Cuzco. Cañete, Lunahuaná, Perú, 68 pp.; New York: Institute of Andean Research, BAR International Series 234.

HYSLOP, J., 1990 - The Settlement planning, 377 pp.; Austin: University of Texas Press.

JIMÉNEZ BORJA, A., 1973 - Imagen del mundo aborigen, 72 pp.; Lima: Editorial Jurídica.

KENDALL, A., 1976 - Descripción e inventario de las formas arquitectónicas inca: patrones de distribución e inferencias cronológicas. Revista del Museo Nacional, Tomo 42: 13-96; Lima.

MATOS, R., 1994 - Pumpu, centro administrativo inka de la puna de Junín, 327 pp.; Lima: Editorial Horizonte.

McCORMAC, G., HOGG, A., BLACKWELL, P., BUCK, C., HIGHAM, T. \& REIMER, P., 2004 - SHCal04 Southern Hemisphere Calibration 0-11.0 cal Kyr BP. Radiocarbon, Vol. 46, n. ${ }^{\mathbf{0}}$ 3: 1087-1092.

McEWAN, G., GIBAJA, A. \& CHATFIELD, M., 1995 - Archaeology of the chokepukio site: an investigation of the origen the inca civilization in the valley of Cuzco, Perú. A report on the 1994 field season. Tahuantinsuyo, una revista internacional de estudios inkas. Vol. 1: 11-17; Australia: Brola Press Pty Ltd.

McEWAN, G., GIBAJA, A. \& CHATFIELD, M., 2005 - Arquitectura monumental en el Cuzco del periodo intermedio tardío: evidencias de continuidades en la reciprocidad ritual y el manejo administrativo entre los horizontes medio y tardío. Boletín de la Pontificia Universidad Católica del Perú. n. o 9: 257-280; Lima. 
Tahuantinsuyo: la arquitectura de los ushnus como espacios de libaciones y ofrendas líquidas

MEDDENS, F., MCEWAN, C., VIVANCO, C., 2010 - Inca "Stone ancestors" in context at high altitude usnu platform. Latin American Antiquity, Vol. 21, n. ${ }^{\circ}$ 2, june: 173194; Society for American Archaeology.

MEDDENS, F., BRANCH, N., VIVANCO, C., RIDDIFORD, N. \& KEMP, R., 2008 - High altitude Ushnu platforms in the Department of Ayacucho Peru, structure, ancestors and animating essence. In: Pre-Columbian landscapes of creation and origin (J. E. Staller, ed.): 315-355; New York.

MOLINA, C. de, 2008 [1574-1575] - Relación de las fábulas y ritos de los Incas, 279 pp.; Lima: Universidad de San Martín de Porres (USMP). Facultad de Ciencias de la Comunicación, Turismo y Psicología. Edición y notas Julio Calvo Pérez y Henrique Urbano.

MONTEVERDE SOTIL, R., 2008 - El ushnu de Piedra Angosta. Revista ARKINKA, revista de arquitectura, diseño y construcción. n. ${ }^{\circ}$ 157: 94-101; Lima.

MONTEVERDE SOTIL, R., 2010 - Cuzco: Capital del Tahuantinsuyo y la fiesta de la Situa. Boletín de Lima. Vol. XXXII, n. ${ }^{\circ}$ 159: 35-53; Lima.

MORRIS, C. \& COVEY, A., 2003 - La plaza central de Huánuco Pampa: espacio y transformación. Boletín de Arqueología PUCP, n. ${ }^{\circ}$ 7: 133-149; Lima.

MORRIS, C. \& THOMPSON, D., 1985 - Huánuco Pampa: an Inca city and its hinterland, 181 pp.; Nueva York: Thames and Hudson.

MURRA, J., 2007 - La organización económica del Estado Inca, 511 pp.; México, D.F.: Siglo XXI.

MURÚA, Fray M. de, 2004 [1590] - Historia y Genealogía de los reyes incas del Perú, 276 pp.; Madrid: Testimonio Compañía Editorial. Códice Galvin. Edición facsímil, Ejemplar 139. Estudio: Juan Ossio.

OBERTI, Í., 1983 - Cuzco arqueológico y etnohistórico: una introducción bibliográfica. Revista Andina, n. ${ }^{\circ}$ 2: 443-473; Cuzco: Centro de Estudios Regionales Andinos Bartolomé de las Casas.

PINO MATOS, J. L., 2004 - Observatorios y alineamientos astronómicos en el Tampu Inka de Huánuco Pampa. Arqueología y Sociedad, n. 15: 173-190; Lima.

PINO MATOS, J. L., 2005. El ushnu y la organización espacial astronómica en la sierra central del Chinchaysuyu. Estudios Atacameños, n. ${ }^{0}$ 29: 143-161; Arica.

PINO MATOS, J. L., 2008 - El ushnu de Huanucopampa, eje de rituales y libaciones. Ponencia dada en el marco de la conferencia «El ushnu inca, arqueología, paisaje y poder»; Lima: Centro Cultural Británico de Miraflores (Septiembre).

PINO MATOS, J. L., 2010 - Yllapa usno: rituales de libación, culto a ancestros y la idea del ushnu en los Andes según los documentos coloniales de los siglos XVI-XVII. Arqueología y Sociedad. Edición Especial (Homenaje a Craig Morris. Los inkas y la interacción de sociedades, paisajes y territorios en los Andes), n. ${ }^{\circ}$ 21: 77-108; Lima.

PIZARRO, P., 1986 [1571] - Relación del descubrimiento y conquista de los reinos del Perú, 277 pp.; Lima: Pontificia Universidad Católica, Fondo Editorial. Guillermo Lohmann Villena (Edición, consideraciones preliminares), Pierre Duviols (Nota).

PRESBíTERO, G., SOBCZYK, M. \& WOLOSZYN, J., 2000-2001 - Plataforma ceremonial del sitio Maucallacta. Andes: Boletín de la Misión Arqueológica Andina de la Universidad de Varsovia. Vol. I, n. ${ }^{\circ}$ 3: 185-199; Varsovia: Universidad de Varsovia, Universidad Católica Santa María de Arequipa. Proyecto Arqueológico Condesuyos.

RAFFINO, R., GOBBO, D., VÁZQUEZ, R., CAPPARELLI, A., MONTES, V., ITURRIZAGA, R., DESCHAMPS, C., MANNASERO, M., 1997 - El ushnu de Shincal de Quimivil. Tahuantinsuyo, una revista internacional de estudios inkas, Vol. 3: 22-39; Australia: Brola Press Pty Ltd. 
ROWE, J. H., 1981 - Una relación de los adoratorios del antiguo Cuzco. Histórica, Vol. V, n. ${ }^{\circ}$ 2: 209-261; Lima: Pontificia Universidad Católica del Perú, Departamento de Humanidades.

SANTA CRUZ PACHACUTI YAMQUI SALCAMAYGUA, J., 1995 [1613] - Relación de Antigüedades deste reyno del Piru, 427 pp.; México DF.: Fondo de Cultura Económico. Carlos Aranibar (Edición, índice y glosario).

SANTILLANA, J., 2001 - Las plazas del Cusco y el espacio ceremonial inca. In: Los dioses del Antiguo Perú: 249-267; Lima: Banco de Crédito del Perú. Colección Arte y Tesoros del Perú, Vol. 2.

SHEA, D., 1966 - El conjunto arquitectónico central en la plaza de Huánuco Viejo. Cuadernos de Investigación, I: 108-116; Lima.

TARRAGO, M. \& GONZÁLEZ, L., 2005 - Variabilidad en los modos arquitectónicos incaicos. Un caso de estudio en el valle de Yocavil (noroeste argentino). Chungara, Revista de antropología chilena, Vol. 37, n. ${ }^{\circ}$ 2: 129-143; Arica: Universidad de Tarapacá. Facultad de Ciencias Sociales Administrativas y Económicas. Departamento de Arqueología y Museología.

TILLEY, C., 1989 - Interpreting material culture. In: The Meanings of Things (I. Hodder, ed.): 185-194; Cambridge: Cambridge University Press..

TOPIC, J., 2008 - El santuario de Catequil: estructura y agencia. Hacia una comprensión de los oráculos andinos. In: Adivinación y oráculos en el mundo andino antiguo (M. Curatola \& M. S. Ziólkowski, eds.): 71-95; Lima: Instituto Francés de Estudios Andino (IFEA), Fondo Editorial de la Pontificia Universidad Católica del Perú (PUCP).

TOPIC, J., LANGE TOPIC, T. \& MELLY, A., 1999 - Las investigaciones en Namanchugo. El oráculo de «Catequil». Informe presentado al INC. Accesible en internet: http:// www.munihuamachuco.gob.pe/milenario/huamachuco/2001.html

TUESTA, S., 2010 - Fiestas. Calendario y costumbres, 320 pp.; Lima: Costumbres Sociedad Anónima Cerrada.

VARGAS PALIZA, E., 2007 - Kusikancha. Morada de las momias reales de los inkas, xx+339 pp.; Cuzco: Instituto Nacional de Cultura (INC-Cuzco). Subdirección de Investigación.

VILLACORTA, L. F., 2003 - Palacios y ushnus: curacas del Rímac y gobierno inca en la costa central. Boletín de Arqueología PUCP, n. ${ }^{\circ}$ 7: 151-187; Lima.

YARANGA VALDERRAMA, A., 1979 - La divinidad illapa en la región andina. América Indígena, Vol. XXXIX, n. ${ }^{\mathbf{0}}$ 4: 697-720; México: Instituto Indigenista Interamericano.

ZIÓLSKOWSKI, M., 1996 - Ataw o de «la guerra justa» en el Tahuantinsuyo. Tahuantinsuyo, una revista internacional de estudios inkas, Vol. 2: 5-22; Australia: Brola Press Pty Ltd.

ZIÓLSKOWSKI, M., 2002 - El Inca y el breviario, o del arte de conversar con las huacas. In: El hombre y los Andes: homenaje a Franklin Pease G.Y., Vol. 2 (J. Flores Espinoza \& R. Varón Gabai, eds.): 597-610; Lima: PUCP. Fondo Editorial.

ZUIDEMA, T., 1979 - El ushnu. Revista de la Universidad Complutense, Vol. 28, n. ${ }^{\circ}$ 117: 317-362; Madrid.

ZUIDEMA, T., 1989 - El ushnu. In: Reyes y guerreros: ensayos de cultura andina (M. Burga, ed.): 402-454; Lima: Asociación Peruana para el fomento de las ciencias sociales FONCIENCIAS.

ZUIDEMA, T., 1991 - La Civilización inca en Cuzco, 160 pp.; México DF.: Fondo de Cultura Económica. 